\title{
Biosynthetic Functionalization of Nonribosomal Peptides
}

David L. Niquille $\$$, Ines B. Folger + , Sophie Basler, Donald Hilvert*

$\$$ Contributed equally; * Corresponding Author

donald.hilvert@org.chem.ethz.ch

Table of Contents

Materials \& Methods

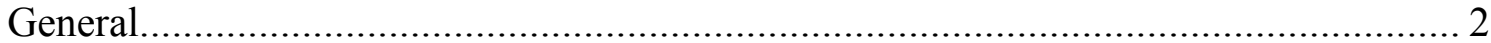

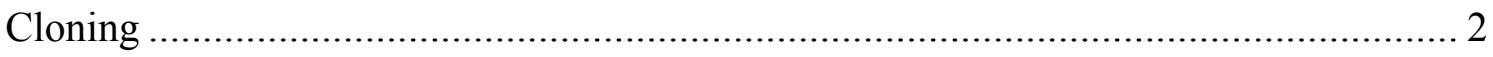

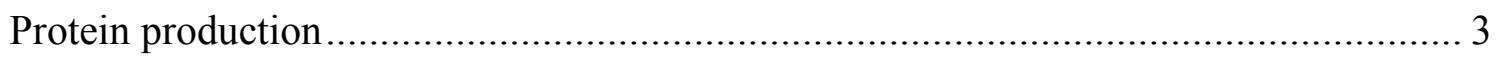

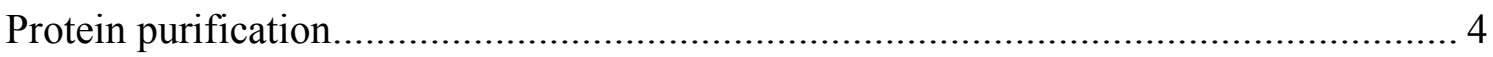

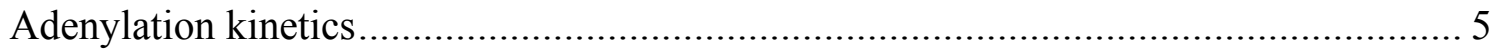

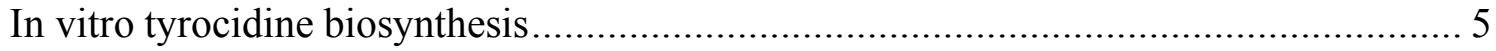

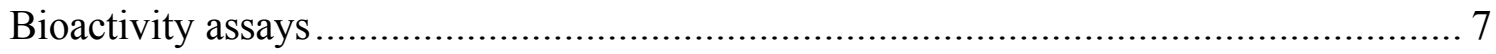

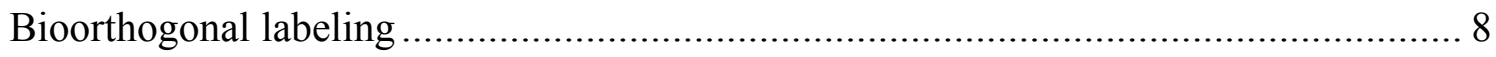

Supporting Tables \& Figures

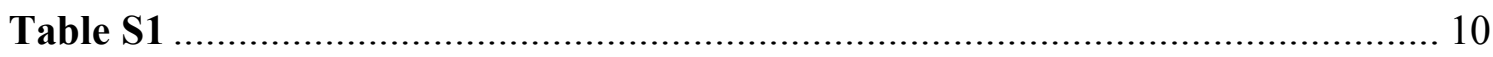

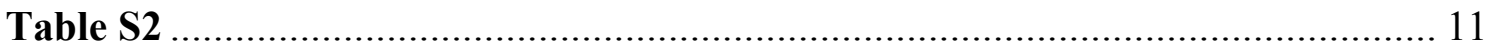

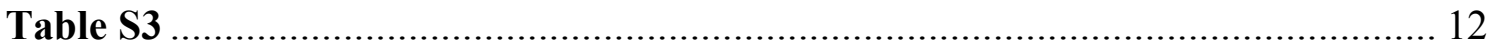

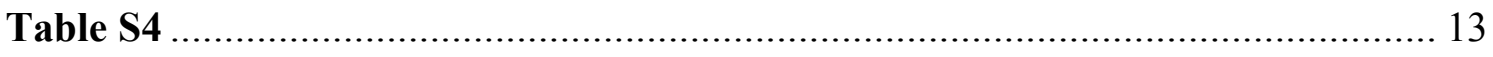

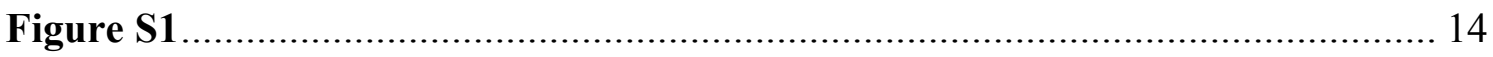

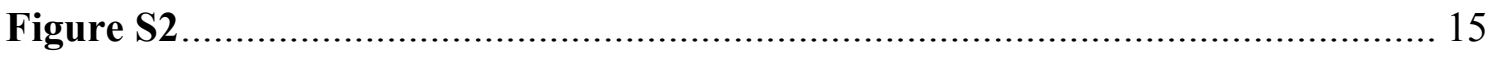

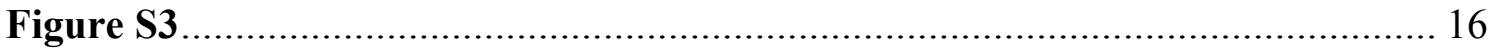

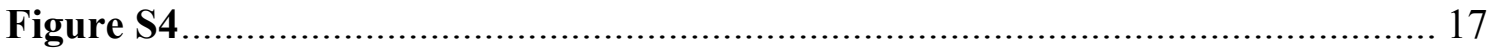

Figure S5

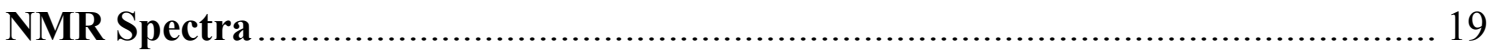

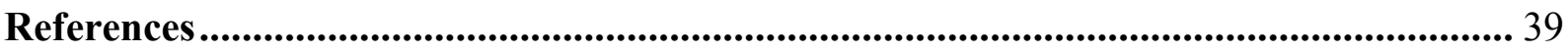




\section{Materials \& Methods}

General. All reagents were used as received and all solvents were HPLC grade. High resolution mass spectrometry (HRMS) was performed on a Bruker maXis UHR-TOF by electrospray ionization (ESI) at the Mass Spectrometry Service of the Laboratory of Organic Chemistry at ETH Zurich. NMR spectra were recorded on a Bruker Avance-III $600 \mathrm{MHz}$ spectrometer at the NMR Service at the LOC, ETH Zurich. ${ }^{1} \mathrm{H}-\mathrm{NMR}$ spectra were recorded relative to residual solvent peak (DMSO- $d_{6} \delta_{\mathrm{H}} 2.50 \mathrm{ppm}$ ) and reported as follows: chemical shift (ppm), multiplicity, coupling constant $(\mathrm{Hz})$, and integration. Multiplicity abbreviations are as follows: $\mathrm{s}=$ singlet, $\mathrm{d}=$ doublet, $\mathrm{t}=$ triplet, $\mathrm{q}=$ quartet, $\mathrm{m}=$ multiplet. ${ }^{13} \mathrm{C}-\mathrm{NMR}$ spectra were recorded relative to residual solvent peaks (DMSO- $d_{6} \delta_{\mathrm{C}} 39.52 \mathrm{ppm}$ ).

Cloning. Expression media and buffers were prepared using purified $\mathrm{H}_{2} \mathrm{O}$ (Nanopure system, Barnstead). Media and buffer components, kits, and enzymes were used as received from specified commercial suppliers. Commercial enzymes were purchased from NEB if not stated otherwise.

Oligonucleotide primers were purchased from Microsynth AG (Switzerland) and all PCRs utilized Phusion HF polymerase (NEB) according to the manufacturer's instructions with the supplied HF buffer ( $50 \mu \mathrm{L}$ total volume, $50 \mathrm{ng}$ plasmid DNA, $0.5 \mu \mathrm{M}$ primer, $0.2 \mathrm{mM}$ dNTPs (Sigma), $1 \mu \mathrm{L}$ Phusion HF). DNA was either purified via agarose gels (1\%) and extracted using a Gel DNA Recovery Kit (Zymo Research) or via spin columns using a DNA clean and concentrator kit (Zymo Research). Transformations were conducted with electrocompetent Escherichia coli HM0079 ${ }^{1}$ cells $\left(100 \mu \mathrm{L}, \sim 100 \mathrm{ng}\right.$ DNA), followed by immediate SOC $(1 \mathrm{~mL})$ rescue and incubation at $37^{\circ} \mathrm{C}$, $400 \mathrm{rpm}$ for $1 \mathrm{~h}$ before plating onto LB agar containing the respective antibiotic. Single colonies were selected and grown in overnight cultures using LB Miller broth (Merck) containing an appropriate antibiotic. After harvesting cells by centrifugation, plasmid DNA was isolated with a ZR Plasmid Miniprep Classic kit (Zymo Research) according to the manufacturer's specifications. All cloned variants were verified by Sanger sequencing at Microsynth AG (Switzerland).

The cloning of plasmids pSU18_tycA and pSU18_tycA_W227S was described previously. ${ }^{1,2}$ Plasmid pTrc99a_tycB for the production of C-terminally His 6 -tagged TycB was constructed by Gibson assembly ${ }^{3}$ of four fragments (pTrc99a, tycB_1, tycB_2, and tycB_3) with 20 bp overlaps, each using a Gibson Assembly cloning kit (NEB) according to manufacturer specifications. The individual fragments were designed to introduce XhoI, SacI, and NotI restriction sites by silent mutation to facilitate subsequent cloning; the ligation sites were chosen accordingly. Fragment A $(4,100 \mathrm{bp})$ was PCR amplified from plasmid $p \operatorname{Trc} 99 \mathrm{a}^{1}$ with primer pair pTrc99a_f / pTrc99a_r. Fragments tycB_1 (4,700 bp), tycB_2 (3,000 bp), and tycB_3 (3,100 bp) were PCR amplified from Brevibacillus parabrevis genomic DNA (DSM 362, tyrocidine producer) with primer pairs tycB_1_f / tycB_1_r, tycB_2_f / tycB_2_r and tycB_3_f / tycB_3_r, respectively. B. parabrevis genomic DNA was isolated and purified by isopropanol precipitation as described previously. ${ }^{1}$ Sequencing of the resulting plasmid showed that the TycB sequence corresponds to GenBank entry HBZ81682. 
To reprogram TycB-A3 for $O$-propargyl-L-Tyr, two fragments were PCR amplified from pTrc99a_tycB with primer pairs tycB_3_f / tycB_W2742S_r and tycB_W2742S_f / tycB_3_r, respectively. The two fragments were assembled by $\mathrm{PCR}$ with primer pair tycB_3_f / tycB_3_r and introduced into pTrc99a_tycB via SacI and NotI restriction sites to yield plasmid pTrc99a_tycB_W2742S.

For the recombinant production of His 6 -tagged TycC, plasmid pTrc99a_tycC was constructed as described for pTrc99a_tycB by Gibson assembly of four fragments. Fragments tycC_1, tycC_2, and tycC_3 were PCR-amplified from $B$. parabrevis gDNA using primer pairs tycC_1_f / tycC_1_r, tycC_2_f / tycC_2_r, and tycC_3 f f / tycC_3_r, respectively. Sequencing of the resulting plasmid showed that the TycC sequence corresponds to GenBank entry HBZ81681.

\begin{tabular}{ll} 
Primer & Sequence 5'-3' \\
\hline pTrc99a_f & GGA TCC AGA TCT CAT CAC CAT CAC \\
pTrc99a_r & CAT GGT ACC TTT CCT GTG TGA AAT TG \\
tyCB_1_f & CAA TTT CAC ACA GGA AAG GTA CCA TGA GTG TAT TTA GCA AAG \\
tycB_1_r & CGC CAT CTC GAG CGA TCT TTG CGC CAT GAT C \\
tycB_2_f & GCA AAG ATC GCT CGA GAT G \\
tycB_2_r & CTC TTT CAT TGA GCT CCC \\
tyCB_3_f & GGG AGC TCA ATG AAA GAG \\
tycB_3_r & GTG ATG GTG ATG AGA TCT GG \\
tyCB_W2742S_f & ATC GGT GTC GGA TAT GTT TGG C \\
tyCB_w2742S_r & AAC ATA TCC GAC ACC GAT GCG TC \\
tycC_1_f & CAA TTT CAC ACA GGA AAG GTA CCA TGA AAA AGC AGG AAA ACA TC \\
tyCC_1_r & GAG TGG AAA CTA GTG CGC AAC GAT TCG \\
tyCC_2_f & TTG CGC ACT AGT TTC CAC TCC GTG CAA G \\
tyCC_2_r & CAT ACA AGC TAG CAA TTT CCT CGA CGA TG \\
tycC_3_f & GGA AAT TGC TAG CTT GTA TGC AGG AAA AC \\
tycC_3_r & GTG ATG GTG ATG AGA TCT GGA TCC TTT CAG GAT GAA CAG TTC TTG \\
\hline
\end{tabular}

Protein production. Protein production was performed in modified Studier medium " "ZYM-G".

$\underline{\text { Modified Studier medium }}$

\begin{tabular}{ll}
\hline \multicolumn{1}{c}{$\mathrm{ZY}$} & tryptone (Merck, $1 \% \mathrm{w} / \mathrm{w}) ;$ yeast extract (Merck, 0.5\% w/w) \\
\hline $50 \times \mathrm{M}$ solution $(20 \mathrm{~mL} / \mathrm{L})$ & $\mathrm{Na}_{2} \mathrm{HPO}_{4}\left(\right.$ Merck, 25 mM); $\mathrm{KH}_{2} \mathrm{PO}_{4}($ Merck, $25 \mathrm{mM}) ;$ \\
& $\mathrm{NH}_{4} \mathrm{Cl}($ Merck, $50 \mathrm{mM}) \mathrm{Na}_{2} \mathrm{SO}_{4}($ Merck, $5 \mathrm{mM})$ \\
\hline $100 \times \mathrm{G}$ solution $(10 \mathrm{~mL} / \mathrm{L})$ & glycerol (Sigma, $50 \% \mathrm{v} / \mathrm{v})$ \\
\hline $500 \times \mathrm{Mg}(\mathrm{II})$ solution $(2 \mathrm{~mL} / \mathrm{L})$ & $\mathrm{MgSO}_{4}($ Merck, $1 \mathrm{M})$ \\
\hline
\end{tabular}


The ZY component was autoclaved, whereas the $\mathrm{M}, \mathrm{G}$, and $\mathrm{Mg}(\mathrm{II})$ components were sterile filtered (TPP, $0.22 \mu \mathrm{m}$ ) before use (note: LB Miller broth (Merck) could be substituted for ZY with no discernible difference). Isopropyl- $\beta$-D-thiogalactopyranoside (IPTG), ampicillin (amp), and chloramphenicol (cam) were obtained from Apollo scientific.

HM0079 cells ${ }^{1}$ harboring the expression plasmids were taken from glycerol cell stocks stored at $-80{ }^{\circ} \mathrm{C}$ and grown overnight at $37^{\circ} \mathrm{C}$ in LB Miller broth $(5 \mathrm{~mL})$ containing the respective antibiotic. The following morning, ZYM-G $(800 \mathrm{~mL}$ in a $2 \mathrm{~L}$ baffled flask $)$ containing the respective antibiotic was inoculated with the overnight culture $(1 / 500 \mathrm{v} / \mathrm{v})$ and shaken at $180 \mathrm{rpm}$ and $37^{\circ} \mathrm{C}$ until an OD600 of 2 was reached, at which point the cultures were cooled to $20^{\circ} \mathrm{C}$. After reaching $20^{\circ} \mathrm{C}$, cell cultures were induced with IPTG $(100 \mu \mathrm{M})$ and shaken at $180 \mathrm{rpm}$ and $20^{\circ} \mathrm{C}$ for $\sim 20$ h. Cells were pelleted at $5,000 \mathrm{x} \mathrm{g}$ and $4{ }^{\circ} \mathrm{C}$ for 25 minutes, transferred to $50 \mathrm{~mL}$ falcon tube(s), and frozen at $-20^{\circ} \mathrm{C}$.

Protein purification. Imidazole, $\mathrm{NaCl}, \mathrm{HEPES}$, and Tris base were obtained from Merck. The $\mathrm{pH}$ of all buffers was adjusted using a WTW bench $\mathrm{pH} / \mathrm{mV}$ meter (routine meter $\mathrm{pH} 526$ ) calibrated according to manufacturer specifications. Cell pellets were thawed and suspended in lysis buffer [3 mL / g cells, Tris $(50 \mathrm{mM}), \mathrm{NaCl}(500 \mathrm{mM})$, glycerol $(10 \% \mathrm{v} / \mathrm{v}), \mathrm{pH} 8.0$ ] via vortex. For lysis, the cell suspension was treated by addition of lysozyme (Sigma, $2 \mathrm{mg} / \mathrm{mL}$ ), polymyxin B (Apollo, $2 \mathrm{mg} / \mathrm{mL}$ ), RNase A (Sigma, $0.04 \mathrm{mg} / \mathrm{mL}$ ) and DNase I (Sigma, $0.04 \mathrm{mg} / \mathrm{mL}$ ) at $4{ }^{\circ} \mathrm{C}$ for $30 \mathrm{~min}$ before sonication (Dr. Heilscher, UP 200s sonic dismembrator, total sonication time of 6 min at $100 \%$ power with care taken to keep internal temperature $<15^{\circ} \mathrm{C}$ ). Cellular debris was pelleted in a pre-cooled $\left(4^{\circ} \mathrm{C}\right)$ centrifuge at $15,000 \mathrm{x}$ g for $25 \mathrm{~min}$ and the supernatant was applied to Ni-NTA resin (Qiagen, $1 \mathrm{~mL} / 4 \mathrm{~g}$ cells, pre-equilibrated with five column volumes of lysis buffer). Wash buffer [10 column volumes, Tris $(50 \mathrm{mM}), \mathrm{NaCl}(500 \mathrm{mM})$, imidazole $(20 \mathrm{mM})$, glycerol $(10 \%$ $\mathrm{v} / \mathrm{v}), \mathrm{pH} 8.0$ ] was added and the column was gently pressurized with a syringe. The enzyme of interest was eluted with elution buffer [3 column volumes, Tris $(50 \mathrm{mM}), \mathrm{NaCl}(500 \mathrm{mM})$, imidazole (300 mM), glycerol (10\% v/v), pH 8.0].

TycA variants were further purified to reduce the endogenous amino acid background in the ${ }^{32} \mathrm{P}-\mathrm{PP} / \mathrm{ATP}$ exchange assay. To that end, buffer was exchanged to FPLC buffer [Tris (20 mM), $\mathrm{NaCl}(20 \mathrm{mM})$, glycerol (5\% v/v), $\mathrm{pH}$ 8.0] using centrifugal filter units (Merck, Amicon Ultra-15) and the proteins were purified by anion-exchange chromatography (GE Health- care, MonoQ $10 / 100$, linear gradient from 0.05 to $0.5 \mathrm{M} \mathrm{NaCl})$. All other proteins were buffer exchanged to storage buffer [HEPES (50 mM), $\mathrm{NaCl}(100 \mathrm{mM}), \mathrm{MgCl}_{2}(10 \mathrm{mM})$, glycerol (10\% v/v), pH 8.0] and aliquoted. Purified proteins were immediately flash frozen in liquid $\mathrm{N}_{2}$ and stored at $-80{ }^{\circ} \mathrm{C}$ until use. Protein concentration was determined using a Nanodrop 2000 spectrophotometer (Thermo Fisher) and corrected by the calculated extinction coefficient (ProtParam, http://web.expasy.org/protparam/). Protein purity was assessed by SDS-PAGE using a Phast system and $7.5 \%$ gels (GE), according to the manufacturer's specifications. 
Adenylation kinetics. Adenylation kinetics were determined with a pyrophosphate exchange assay as described in Kries et al. ${ }^{2}$. The L-Phe analogs $p$-bromo-L-Phe, $p$-iodo-L-Phe and $p$-benzoylL-Phe were purchased from Chem-Impex. $O$-Propargyl-L-Tyr was synthesized as previously described. $^{2}$

In vitro tyrocidine biosynthesis. Enzymatic reactions for in vitro tyrocidine production were performed in Bis-Tris propane buffer ( $100 \mathrm{mM}, 100 \mathrm{mM} \mathrm{NaCl}, 10 \mathrm{mM} \mathrm{MgCl}_{2}, 4 \mathrm{mM}$ tris(2-carboxyethyl)phosphine (TCEP), $50 \mathrm{mM} \mathrm{ATP}, 1 \mathrm{mg} / \mathrm{mL}$ BSA (Sigma), 0.1 units $/ \mathrm{mL}$ inorganic pyrophosphatase from baker's yeast (Merck), $\mathrm{pH} 8)$ with TycA or W227S TycA $(1 \mu \mathrm{M})$, TycB or W2742S TycB $(1 \mu \mathrm{M})$, TycC $(1 \mu \mathrm{M})$ and all substrate amino acids (4 mM L-Phe, $2 \mathrm{mM}$ L-Pro, 2 mM L-Asn, 2 mM L-Gln, 2 mM L-Tyr, 2 mM L-Val, 2 mM L-Orn, 2 mM L-Leu, and $2 \mathrm{mM} \mathrm{L-}$ Phe or analog). Reactions were started by $\mathrm{TycC}$ addition and incubated at $37{ }^{\circ} \mathrm{C}$ in a water bath. After 6-7 h, the samples $(20 \mu \mathrm{L})$ were quenched with $180 \mu \mathrm{L} \mathrm{MeOH}$, vortexed, clarified by centrifugation (21,000 x g, $10 \mathrm{~min}$ ), and analyzed by HPLC (Ultimate 3000, Dionex) or LC-MS.

For HPLC analyses, a $5 \mu \mathrm{L}$ aliquot was injected onto a Dr. Maisch Reprosil-Gold C18 column $(100 \times 2 \mathrm{~mm}, 3 \mu \mathrm{m})$, monitored at $220 \mathrm{~nm}, 254 \mathrm{~nm}$ and $280 \mathrm{~nm}$. Products were separated by gradient elution: solvent $\mathrm{A}=\mathrm{H}_{2} \mathrm{O}+0.1 \%$ TFA, solvent $\mathrm{B}=\mathrm{MeCN}+0.1 \%$ TFA, flow rate $=1$ $\mathrm{mL} / \mathrm{min}, 0-0.5 \mathrm{~min}=5 \% \mathrm{~B}, 0.5-1.5 \mathrm{~min}$ ramp to $55 \% \mathrm{~B}, 1.5-4.0 \mathrm{~min}$ ramp to $82.5 \% \mathrm{~B}, 4.0-5.2$ $\min =99 \% \mathrm{~B}, 5.2-5.6 \mathrm{~min}$ ramp to $5 \% \mathrm{~B}, 5.6-6.5 \mathrm{~min}$ re-equilibration $=5 \% \mathrm{~B}$. LC-MS (Waters H-class UPLC/SQD-2) analyses were performed on an Acquity UPLC BEH C-18 column (50 x $2.1 \mathrm{~mm}, 1.7 \mu \mathrm{m}), 1 \mu \mathrm{L}$ injection, monitoring $\mathrm{ESI}^{+}$for $[\mathrm{M}+2 \mathrm{H}]^{2+}$, solvent $\mathrm{A}=\mathrm{H}_{2} \mathrm{O}+0.1 \% \mathrm{FA}$, solvent $\mathrm{B}=\mathrm{MeCN}+0.1 \% \mathrm{FA}$, flow rate $=1 \mathrm{~mL} / \mathrm{min}$, initial conditions $=5 \% \mathrm{~B}, 0-1.5 \mathrm{~min} \mathrm{ramp}$ to $80 \% \mathrm{~B}, 1.5-2 \mathrm{~min}$ ramp to $100 \% \mathrm{~B}, 2-2.2 \mathrm{~min}=100 \% \mathrm{~B}, 2.2-2.3 \mathrm{~min}$ ramp to $5 \% \mathrm{~B}, 2.3-3 \mathrm{~min}$ re-equilibration $=5 \% \mathrm{~B}$. Reaction products were identified by liquid chromatography high-resolution mass spectrometry (LC-HRMS) on a Bruker maXis UHR-TOF by electrospray ionization using an Eclipse Plus C18 column (Agilent), monitoring m/z 100-5000 with $\mathrm{m} / \mathrm{z} 622.029$ as a reference: solvent $\mathrm{A}=\mathrm{H}_{2} \mathrm{O}+0.1 \%$ formic acid, solvent $\mathrm{B}=\mathrm{MeCN}+0.1 \%$ formic acid, flow rate $=0.6 \mathrm{~mL} / \mathrm{min}, 0-1 \mathrm{~min}=5 \% \mathrm{~B}, 1-2 \mathrm{~min}$ ramp to $55 \% \mathrm{~B}, 2-7.5 \mathrm{~min}$ ramp to $85 \% \mathrm{~B}, 7.51-9 \mathrm{~min}=$ $99 \% \mathrm{~B}, 9.01-14 \mathrm{~min}=5 \% \mathrm{~B}$.

Rate constants $\left(k_{\mathrm{obs}}\right)$ and total turnover numbers for formation of tyrocidine A (1) and analogues 2 and 7 were determined in time course experiments. The reactions were performed in a total volume of $200 \mu \mathrm{L}$. After 15, 30, 45, 60, 75, $90 \mathrm{~min}$ and 6-7 h, $20 \mu \mathrm{L}$ aliquots were worked up and analyzed as described above. Authentic standards were used for product quantification at $220 \mathrm{~nm}$. Three biological replicates were used to determine total turnovers and $k_{\text {obs }}$ values. Because compound 2 could not be separated from wild-type tyrocidine A (1) under the standard UPLC conditions, the product ratio was determined independently by separating the mixture on a Reprospher 100 Phenyl-hexyl column ( 125 x $4.6 \mathrm{~mm}, 5 \mu \mathrm{m}$; Dr. Maisch GmbH HPLC), $5 \mu \mathrm{L}$ injection, monitored at $220 \mathrm{~nm}, 254 \mathrm{~nm}$ and $280 \mathrm{~nm}$, solvent $\mathrm{A}=\mathrm{H} 2 \mathrm{O}+0.1 \%$ TFA, solvent $\mathrm{B}=\mathrm{MeCN}+0.1 \%$ TFA, flow rate $=1 \mathrm{~mL} / \mathrm{min}, 0-1 \mathrm{~min}=5 \% \mathrm{~B}, 1-3 \mathrm{~min}$ ramp to $55 \% \mathrm{~B}, 3-16 \mathrm{~min}$ ramp to $95 \% \mathrm{~B}$, 16-19 $\min 95 \%$ B, $19-19.5$ ramp to $5 \%$ B, 19.5-22 min re-equilibration $=5 \%$ B (see Figure S4). 
Preparative biosynthesis of tyrocidine A (1) and propargylated analogues 2 and 7. Larger scale NRP biosynthesis was performed as described above but in a total volume of $300 \mathrm{~mL}$ for $\mathbf{1}$, $25 \mathrm{~mL}$ for $\mathbf{2}$ and $130 \mathrm{~mL}$ for $\mathbf{7}$. For compound $\mathbf{2}$, the reaction was supplemented with $20 \mathrm{mM} O-$ propargyl-L-Tyr to suppress side product formation. All large-scale reactions were incubated at $37{ }^{\circ} \mathrm{C}$ for $8-10$ hours and aliquots of the reactions were quenched with $\mathrm{MeOH}$, and analyzed by HPLC and LC-MS as described above.

After 8-10 hours, precipitated tyrocidines were isolated by centrifugation and the supernatants were discarded. The solid products were dissolved in 1:1 DMSO:MeOH and remaining enzymes were removed by centrifugation $(7,000 \mathrm{x}$ g, $20 \mathrm{~min})$. The resulting supernatants were filtered over a syringe filter (Macherey-Nagel, $0.45 \mu \mathrm{m}$, PTFE) and purified by preparative HPLC (Waters) on a Gemini $5 \mu \mathrm{m}$ NX-C18 110 Å LC column (250 x 21.2 mm, Phenomenex Inc. Basel, Switzerland), $10 \mathrm{~mL}$ injection, monitoring with a diode array detector at $220 \mathrm{~nm}$ and $254 \mathrm{~nm}$, solvent $\mathrm{A}=\mathrm{H}_{2} \mathrm{O}$ $+0.1 \% \mathrm{TFA}$, solvent $\mathrm{B}=\mathrm{MeCN}+0.1 \% \mathrm{TFA}$, flow rate $=25 \mathrm{~mL} / \mathrm{min}, 0-2.5 \mathrm{~min}=5 \% \mathrm{~B}, 2.5-7.0$ $\min \operatorname{ramp}$ to $55 \% \mathrm{~B}, 7.0-18.5 \mathrm{~min}=82.5 \% \mathrm{~B}, 18.5-19 \min \operatorname{ramp}$ to $99 \% \mathrm{~B}, 19-24 \mathrm{~min}=99 \% \mathrm{~B}$, 24-26 min ramp to 5\% B, 26-30 min re-equilibration $=5 \% \mathrm{~B}$. Individual fractions were analyzed by HPLC and LC-MS, pure fractions were combined and the solvent was removed under high vacuum to yield the (modified) tyrocidine analogue.

Tyrocidine A (1): $26 \mathrm{mg}$; HRMS: calculated $[\mathrm{M}+\mathrm{H}]^{+}$1270.6619, found 1270.6600 .

${ }^{1} \mathrm{H}$ NMR (600 MHz, DMSO-d $) \delta 9.27(\mathrm{~d}, J=3.7 \mathrm{~Hz}, 1 \mathrm{H}), 9.17$ (s, 1H), 9.04 (m, 2H), 8.89 (d, $J$ $=9.3 \mathrm{~Hz}, 1 \mathrm{H}), 8.71(\mathrm{~d}, J=4.7 \mathrm{~Hz}, 1 \mathrm{H}), 8.42(\mathrm{~d}, J=9.7 \mathrm{~Hz}, 1 \mathrm{H}), 8.02(\mathrm{~s}, 1 \mathrm{H}), 7.91(\mathrm{~d}, J=8.1 \mathrm{~Hz}$, 1H), $7.48-7.37(\mathrm{~m}, 5 \mathrm{H}), 7.27-7.14(\mathrm{~m}, 13 \mathrm{H}), 7.13-7.02(\mathrm{~m}, 4 \mathrm{H}), 6.94-6.88(\mathrm{~m}, 3 \mathrm{H}), 6.62(\mathrm{~d}$, $J=8.2 \mathrm{~Hz}, 2 \mathrm{H}), 5.58(\mathrm{~m}, 1 \mathrm{H}), 5.28(\mathrm{~m}, 1 \mathrm{H}), 4.58-4.44(\mathrm{~m}, 4 \mathrm{H}), 4.33-4.27(\mathrm{~m}, 2 \mathrm{H}), 4.06(\mathrm{~d}, J$ $=8.0 \mathrm{~Hz}, 1 \mathrm{H}), 3.83-3.79(\mathrm{~m}, 1 \mathrm{H}), 3.37-3.27(\mathrm{~m}, 2 \mathrm{H}), 3.08-2.67(\mathrm{~m}, 9 \mathrm{H}), 2.25-2.10(\mathrm{~m}, 3 \mathrm{H})$, $2.04-1.95(\mathrm{~m}, 2 \mathrm{H}), 1.90-1.60(\mathrm{~m}, 7 \mathrm{H}), 1.52-1.32(\mathrm{~m}, 3 \mathrm{H}), 1.28-1.11(\mathrm{~m}, 2 \mathrm{H}), 1.06-0.98$ $(\mathrm{m}, 1 \mathrm{H}), 0.95-0.85(\mathrm{~m}, 12 \mathrm{H}), 0.42-0.31(\mathrm{~m}, 1 \mathrm{H})$.

${ }^{13} \mathrm{C}$ NMR $\left(151 \mathrm{MHz}, \mathrm{DMSO}-d_{6}\right) \delta 174.5,173.0,172.2,171.9,171.0,170.8,170.8,170.6,170.3$, $170.2,169.8,169.2,155.7,138.5,137.3,136.1,129.7,129.3,129.2,128.9,128.2,128.1,127.9$, $127.8,126.9,126.2,126.1,114.9,59.6,56.8,56.2,55.0,54.1,53.5,52.7,50.3,50.1,49.1,45.7$, $41.5,40.1,38.6,37.1,36.9,35.5,35.0,31.5,31.1,31.0,28.5,25.7,24.6,23.0,22.8,22.2,21.9$, $18.7,17.9$.

Propargylated tyrocidine analogue 2: $0.6 \mathrm{mg}$; HRMS: calculated $[\mathrm{M}+\mathrm{Na}]^{+} 1346.6544$, found 1346.6525. An additional $3.7 \mathrm{mg} 2$ containing $\sim 8 \% 1$ was also obtained.

${ }^{1} \mathrm{H}$ NMR (600 MHz, DMSO-d6) $\delta 9.30$ (br s, 3H), 9.06 (d, $\left.J=6.8 \mathrm{~Hz}, 1 \mathrm{H}\right), 8.91$ (d, $J=9.8 \mathrm{~Hz}$, $1 \mathrm{H}), 8.76(\mathrm{~d}, J=9.2 \mathrm{~Hz}, 1 \mathrm{H}), 8.68(\mathrm{~d}, J=4.2 \mathrm{~Hz}, 1 \mathrm{H}), 8.52(\mathrm{~s}, 1 \mathrm{H}), 8.45(\mathrm{~d}, J=9.5 \mathrm{~Hz}, 1 \mathrm{H}), 8.13$ $-7.96(\mathrm{~m}, 2 \mathrm{H}), 7.43-7.01(\mathrm{~m}, 17 \mathrm{H}), 6.95-6.79(\mathrm{~m}, 5 \mathrm{H}), 6.62(\mathrm{~d}, J=8.5 \mathrm{~Hz}, 2 \mathrm{H}), 5.68-5.59$ $(\mathrm{m}, 1 \mathrm{H}), 5.33-5.24(\mathrm{~m}, 1 \mathrm{H}), 4.72(\mathrm{~d}, J=2.3 \mathrm{~Hz}, 2 \mathrm{H}), 4.61-4.43(\mathrm{~m}, 4 \mathrm{H}), 4.33-4.26(\mathrm{~m}, 1 \mathrm{H})$, $4.25-4.18(\mathrm{~m}, 1 \mathrm{H}), 4.05(\mathrm{~d}, J=8.0 \mathrm{~Hz}, 1 \mathrm{H}), 3.80-3.76(\mathrm{~m}, 1 \mathrm{H}), 3.50-3.47(\mathrm{~m}, 1 \mathrm{H}), 3.35-$ 
$3.32(\mathrm{~m}, 1 \mathrm{H}), 3.25-3.22(\mathrm{~m}, 1 \mathrm{H}), 3.09-2.55(\mathrm{~m}, 10 \mathrm{H}), 2.26-2.13(\mathrm{~m}, 2 \mathrm{H}), 2.07-1.95(\mathrm{~m}, 3 \mathrm{H})$, $1.93-1.83(\mathrm{~m}, 1 \mathrm{H}), 1.66-1.59(\mathrm{~m}, 5 \mathrm{H}), 1.51-1.36(\mathrm{~m}, 4 \mathrm{H}), 1.31-1.27(\mathrm{~m}, 1 \mathrm{H}), 1.06-1.00$ $(\mathrm{m}, 1 \mathrm{H}), 0.96-0.86(\mathrm{~m}, 12 \mathrm{H}), 0.38-0.28(\mathrm{~m}, 1 \mathrm{H})$.

${ }^{13} \mathrm{C}$ NMR $\left(151 \mathrm{MHz}, \mathrm{DMSO}-d_{6}\right) \delta 174.5,173.0,171.9,171.8,171.0,170.8,170.7,170.6,170.4$, $170.1,169.4,169.4,156.0,155.8,138.6,137.4,130.3,129.7,129.3,129.0,128.9,128.1,127.8$, 127.7, 126.0, 126.0, 114.9, 114.6, 79.2, 78.0, 59.3, 56.9, 56.2, 55.3, 55.1, 54.3, 53.3, 52.4, 51.1, $50.3,49.1,45.5,41.7,40.4,40.3,37.1,37.0,35.0,34.7,31.5,31.3,31.2,28.4,25.7,24.6,24.0$, 23.0, 22.2, 21.9, 18.8, 17.7 .

Propargylated tyrocidine analogue 7: $25 \mathrm{mg}$; HRMS: calculated $[\mathrm{M}+\mathrm{H}]^{+} 1324.6725$, found 1324.6696. An additional $20 \mathrm{mg} 7$ containing $\sim 3 \% 1$ was also obtained.

${ }^{1} \mathrm{H}$ NMR (600 MHz, DMSO- $\left.d_{6}\right) \delta 9.27(\mathrm{~d}, J=3.7 \mathrm{~Hz}, 1 \mathrm{H}), 9.18(\mathrm{~s}, 1 \mathrm{H}), 9.04-8.98(\mathrm{~m}, 2 \mathrm{H}), 8.88$ $(\mathrm{d}, J=9.3 \mathrm{~Hz}, 1 \mathrm{H}), 8.70(\mathrm{~d}, J=4.7 \mathrm{~Hz}, 1 \mathrm{H}), 8.42(\mathrm{~d}, J=9.7 \mathrm{~Hz}, 1 \mathrm{H}), 8.05-7.94(\mathrm{~m}, 2 \mathrm{H}), 7.49-$ $7.38(\mathrm{~m}, 5 \mathrm{H}), 7.27-7.15(\mathrm{~m}, 11 \mathrm{H}), 7.13-7.06(\mathrm{~m}, 3 \mathrm{H}), 6.95-6.88(\mathrm{~m}, 3 \mathrm{H}), 6.71-6.66(\mathrm{~m}, 2 \mathrm{H})$, $6.62(\mathrm{~d}, J=8.0 \mathrm{~Hz}, 2 \mathrm{H}), 5.58-5.50(\mathrm{~m}, 1 \mathrm{H}), 5.32-5.23(\mathrm{~m}, 1 \mathrm{H}), 4.60-4.47(\mathrm{~m}, 6 \mathrm{H}), 4.34-$ $4.27(\mathrm{~m}, 2 \mathrm{H}), 4.07(\mathrm{~d}, J=8.2 \mathrm{~Hz}, 1 \mathrm{H}), 3.83-3.79(\mathrm{~m}, 1 \mathrm{H}), 3.37-3.27(\mathrm{~m}, 2 \mathrm{H}), 3.19(\mathrm{t}, J=2.4$ $\mathrm{Hz}, 1 \mathrm{H}), 3.05-2.72(\mathrm{~m}, 8 \mathrm{H}), 2.71-2.63(\mathrm{~m}, 1 \mathrm{H}), 2.29(\mathrm{~d}, J=8.1 \mathrm{~Hz}, 2 \mathrm{H}), 2.21-2.13(\mathrm{~m}, 1 \mathrm{H})$, $2.05-1.94(\mathrm{~m}, 2 \mathrm{H}), 1.90-1.60(\mathrm{~m}, 7 \mathrm{H}), 1.49-1.39(\mathrm{~m}, 3 \mathrm{H}), 1.29-1.14(\mathrm{~m}, 2 \mathrm{H}), 1.08-0.98(\mathrm{~m}$, $1 \mathrm{H}), 0.96-0.87(\mathrm{~m}, 12 \mathrm{H}), 0.43-0.33(\mathrm{~m}, 1 \mathrm{H})$.

${ }^{13} \mathrm{C}$ NMR (151 MHz, DMSO- $\left.d_{6}\right) \delta 174.5,173.0,172.3,171.9,171.0,170.8,170.7,170.6,170.3$, $170.2,169.9,169.2,155.8,155.7,138.5,136.1,130.0,129.9,129.7,129.3,128.9,128.2,128.0$, $127.9,126.9,126.1,114.9,114.2,78.9,77.6,59.6,56.8,56.2,55.5,55.0,54.1,53.4,52.6,50.3$, $49.1,45.8,41.3,40.1,38.6,37.1,37.0,35.5,35.0,31.5,31.1,31.0,29.2,28.5,25.7,24.7,23.2$, $22.8,22.1,21.9,18.7,18.0$.

Bioactivity assays. Bioactivity was tested against E. coli HM0079, ${ }^{1}$ Acinetobacter baumannii (ATCC 19606), Bacillus subtilis JH642, ${ }^{5}$ and Staphylococcus aureus (ATCC 43300). A single colony of each strain was regrown in $5 \mathrm{~mL}$ Mueller Hinton Broth (MHB) at $37^{\circ} \mathrm{C}$ and $180 \mathrm{rpm}$ overnight. The next morning, each culture was diluted to $\sim 1 \times 10^{6} \mathrm{CFU} / \mathrm{mL}$ in MHB. Serial dilutions of the tyrocidines from $200 \mu \mathrm{M}$ to $0.4 \mu \mathrm{M}$ were prepared in MHB supplemented with $12 \%$ DMSO. In 96-well plates, $50 \mu \mathrm{L}$ of the respective tyrocidine dilution were added to $50 \mu \mathrm{L}$ of respective strain in MHB (6\% final DMSO concentration) and incubated for 14 hours at $37^{\circ} \mathrm{C}$ and $180 \mathrm{rpm}$. Inhibition of growth was evaluated by eye and by $\mathrm{OD}_{600}$ measurement on a SpectraMax 250 plate reader (Molecular Devices ). Each well was prepared in duplicate and controls with MHB only or MHB supplemented with $6 \%$ DMSO were included in each row. As a sterile control, each serial dilution of the tyrocidines was prepared in duplicate in MHB containing 6\% DMSO without addition of a bacterial strain. The experiment for each tyrocidine analog was conducted in duplicate or triplicate. 
Human blood was purchased from Interregionale Blutspende SRK AG Bern. Erythrocytes were isolated by centrifugation at $500 \mathrm{x} \mathrm{g}$ and $4{ }^{\circ} \mathrm{C}$ for $5 \mathrm{~min}$, washed three times with $150 \mathrm{mM} \mathrm{NaCl}$ and two times with PBS buffer (10 mM Na $2 \mathrm{HPO}_{4}, 1.8 \mathrm{mM} \mathrm{KH}_{2} \mathrm{PO}_{4}, 2.7 \mathrm{mM} \mathrm{KCl}, 137 \mathrm{mM} \mathrm{NaCl}$, $\mathrm{pH}$ 7.4) and diluted 50-fold in PBS. Serial dilutions of the tyrocidines from $2 \mathrm{mM}$ to $4 \mu \mathrm{M}$ were prepared in 6:4 PBS:MeOH. In 96-well plates, $5 \mu \mathrm{L}$ of respective tyrocidine dilution were added to $95 \mu \mathrm{L}$ of erythrocytes in PBS (2\% final $\mathrm{MeOH}$ concentration) and incubated for 1 hour at 37 ${ }^{\circ} \mathrm{C}$ and $700 \mathrm{rpm}$. Intact erythrocytes were separated from hemoglobin in solution by centrifugation at $500 \mathrm{x} \mathrm{g}$ and RT for $10 \mathrm{~min}$. The supernatant was transferred to a fresh 96-well plate and hemolysis was monitored by absorbance of the solution at $405 \mathrm{~nm}$ on a SpectraMax 250 platereader (Molecular Devices). Each well was prepared in duplicate and controls with erythrocytes in PBS only, erythrocytes in PBS containing 2\% MeOH and erythrocytes in PBS containing 1\% Triton X100 were included for each dilution series. The experiment for each tyrocidine analog was conducted in duplicate.

\section{Bioorthogonal labeling of propargylated tyrocidine analogues}
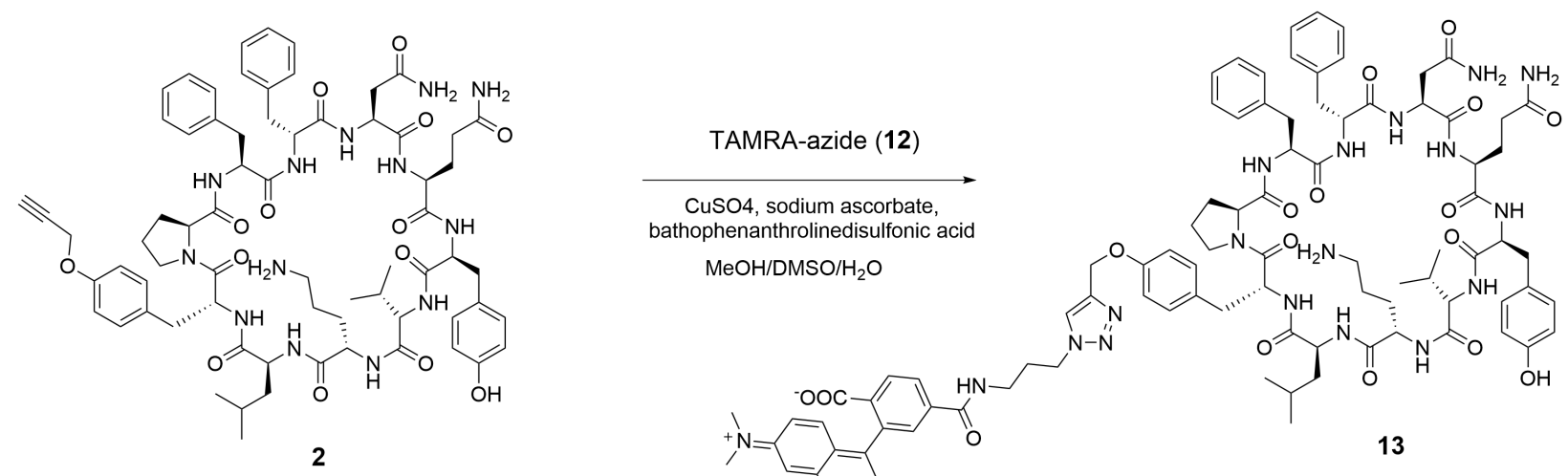

13

TAMRA-modified tyrocidine 13: Tyrocidine analogue $2(2.0 \mathrm{mg}, 1.5 \mu \mathrm{mol}, 1 \mathrm{eq}$. , dissolved in $151 \mu \mathrm{L}$ DMSO) and 6-TAMRA-azide (12, Lumiprobe, $1.2 \mathrm{mg}, 2.3 \mu \mathrm{mol}, 1.5$ eq. dissolved in 114 $\mu \mathrm{L} \mathrm{MeOH}$ ) were mixed in a $1.5 \mathrm{~mL}$ glass vial. $151 \mu \mathrm{L}$ of click mix $\left[\mathrm{CuSO}_{4}\right.$ (Sigma, $0.32 \mathrm{mg}, 2.0$ $\mu \mathrm{mol}, 1.3$ equiv), sodium ascorbate (ABCR, $3.2 \mathrm{mg} 16 \mu \mathrm{mol}, 11$ equiv) and bathophenanthrolinedisulfonic acid disodium salt hydrate (ABCR, $2.0 \mathrm{mg} 3.2 \mu \mathrm{mol}, 2.1$ eq.) in water] were added to the solution and the reaction was run for $30 \mathrm{~min}$ at $\mathrm{RT}$, quenched by dilution in $\mathrm{MeOH}$, and stored at $-20{ }^{\circ} \mathrm{C}$ until purification. Preparative HPLC was performed as described above. Although the reaction ran to completion, separation of $\mathbf{1 3}$ from the corresponding tyrosine analogue $\mathbf{6}$, which was formed as a minor side product during the click reaction, proved difficult. Fractions containing pure product were combined and the solvent was removed under high vacuum to afford pure $\mathbf{1 3}$ $(0.81 \mathrm{mg}, 0.44 \mu \mathrm{mol}, 29 \%)$ as a pink solid. HRMS: calculated $[\mathrm{M}+2 \mathrm{H}]^{2+} 918.9485$, found 918.9459 . 

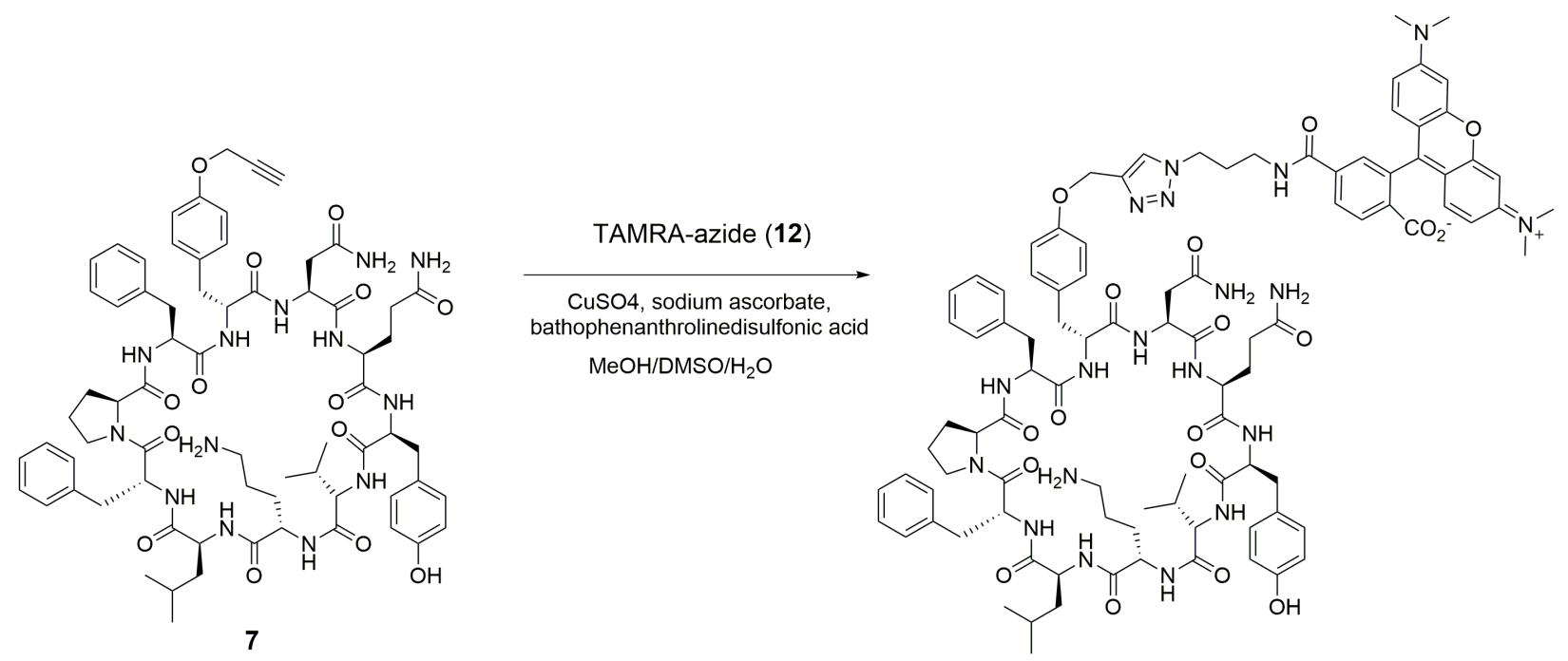

14

TAMRA-modified tyrocidine 14: Tyrocidine analogue 7 (7.9 $\mathrm{mg}, 6 \mu \mathrm{mol}, 1$ eq. dissolved in 600 $\mu \mathrm{L}$ DMSO) and 6-TAMRA-azide (12, Lumiprobe, $4.6 \mathrm{mg}, 9 \mu \mathrm{mol}, 1.1$ eq. dissolved in $450 \mu \mathrm{L}$ $\mathrm{MeOH}$ ) were mixed in a $5 \mathrm{~mL}$ glass vial. $600 \mu \mathrm{L}$ of click mix [CuSO 4 (Sigma, $0.8 \mathrm{mg}, 4.8 \mu \mathrm{mol}$, 0.6 equiv), sodium ascorbate (Sigma, $8.0 \mathrm{mg} 40 \mu \mathrm{mol}, 6.8$ equiv) and bathophenanthrolinedisulfonic acid disodium salt hydrate (Sigma, $4.6 \mathrm{mg} 7.8 \mu \mathrm{mol}, 1$ eq.) in water] were added to the solution and the reaction was run for $15 \mathrm{~min}$ at RT. The reaction was quenched by dilution in $\mathrm{MeOH}$ and the solution stored at $-20{ }^{\circ} \mathrm{C}$ until purification. Preparative HPLC was performed as described above. Although the reaction ran to completion, separation of $\mathbf{1 4}$ from the corresponding tyrosine analogue 11, which was formed as a minor side product during the click reaction, proved difficult. Fractions containing pure product were combined and solvent was removed under high vacuum to afford $14(3.0 \mathrm{mg}, 1.6 \mu \mathrm{mol}, 26 \%)$ as a pink solid. HRMS: calculated $[\mathrm{M}+2 \mathrm{H}]^{2+}$ 918.9485, found 918.9479 .

${ }^{1} \mathrm{H}$ NMR (600 MHz, DMSO- $\left.d_{6}\right) \delta 9.27(\mathrm{~d}, J=3.5 \mathrm{~Hz}, 1 \mathrm{H}), 9.18(\mathrm{~s}, 1 \mathrm{H}), 9.05-8.98(\mathrm{~m}, 2 \mathrm{H}), 8.86$ $(\mathrm{d}, J=9.4 \mathrm{~Hz}, 1 \mathrm{H}), 8.79$ (br s, $1 \mathrm{H}, \mathrm{TAMRA}), 8.71(\mathrm{~d}, J=4.1 \mathrm{~Hz}, 1 \mathrm{H}), 8.40(\mathrm{~d}, J=9.6 \mathrm{~Hz}, 1 \mathrm{H})$, $8.35-8.10$ (br m, 2H, TAMRA), $8.08-7.95$ (m, 3H), $8.09-7.74$ (br m, 1H, TAMRA), $7.48-$ $7.36(\mathrm{~m}, 5 \mathrm{H}), 7.28-7.17(\mathrm{~m}, 10 \mathrm{H}), 7.11-7.05(\mathrm{~m}, 4 \mathrm{H}), 6.95-6.89(\mathrm{~m}, 3 \mathrm{H}), 6.74(\mathrm{~d}, J=8.6 \mathrm{~Hz}$, $2 \mathrm{H}), 6.64-6.60(\mathrm{~m}, 2 \mathrm{H}), 7.22-6.67$ (br m, 6H, TAMRA), $5.57-5.50(\mathrm{~m}, 1 \mathrm{H}), 5.30-5.23(\mathrm{~m}$, $1 \mathrm{H}), 4.92-4.85(\mathrm{~m}, 2 \mathrm{H}), 4.57-4.46(\mathrm{~m}, 4 \mathrm{H}), 4.37-4.26(\mathrm{~m}, 4 \mathrm{H}$, two of TAMRA), 4.07 (d, $J=$ $8.3 \mathrm{~Hz}, 1 \mathrm{H}), 3.81$ (q, $J=6.2 \mathrm{~Hz}, 1 \mathrm{H}), 3.32-3.30$ (m, 2H), $3.27-2.70$ (br m, 14H, TAMRA), 3.08 $-2.63(\mathrm{~m}, 9 \mathrm{H}), 2.35-2.27(\mathrm{~m}, 2 \mathrm{H}), 2.21-2.14(\mathrm{~m}, 1 \mathrm{H}), 2.06-1.93$ (m, 4H, two of TAMRA), $1.89-1.75(\mathrm{~m}, 2 \mathrm{H}), 1.74-1.59(\mathrm{~m}, 5 \mathrm{H}), 1.48-1.36(\mathrm{~m}, 3 \mathrm{H}), 1.28-1.14(\mathrm{~m}, 2 \mathrm{H}), 1.08-1.00$ $(\mathrm{m}, 1 \mathrm{H}), 0.92-0.75(\mathrm{~m}, 12 \mathrm{H}), 0.43-0.33(\mathrm{~m}, 1 \mathrm{H})$.

${ }^{13} \mathrm{C}$ NMR $\left(151 \mathrm{MHz}, \mathrm{DMSO}-d_{6}\right) \delta 174.5,173.0,172.3,171.9,171.0,170.8,170.7,170.7,170.3$, 170.2 , 169.8, 169.2, 164.7, 156.7, 155.7, 142.6, 138.5, 136.1, 130.1, 129.7, 129.6, 129.3, 128.8, $128.2,128.0,127.9,126.9,126.1,124.1,114.9,114.0,61.4,59.6,56.8,56.2,55.0,54.1,53.4,52.6$, $50.4,50.3,49.1,47.3,45.7,41.3,39.1,38.54,37.1,37.0,36.7,35.5,35.0,31.4,31.1,31.0,29.7$, $28.5,25.7,24.6,23.1,22.8,22.0,21.9,18.7,17.9$. 
Table S1. Catalytic parameters for pyrophosphate exchange ${ }^{a}$

\begin{tabular}{|c|c|c|c|c|}
\hline TycA & Substrate & $\begin{array}{l}k_{\text {cat }} \\
\left(\min ^{-1}\right)\end{array}$ & $\begin{array}{l}K_{M} \\
(\mathbf{m M})\end{array}$ & $\begin{array}{l}k_{\text {cat }} / K_{M} \\
\left(\mathrm{mM}^{-1} \mathrm{~min}^{-1}\right)\end{array}$ \\
\hline \multirow[t]{5}{*}{ wt } & L-Phe ${ }^{b}$ & $300 \pm 20$ & $0.011 \pm 0.002$ & $27,000 \pm 8,000$ \\
\hline & $O$-propargyl-L-Tyr & n.d. ${ }^{\mathrm{c}}$ & n.d. ${ }^{\mathrm{c}}$ & $2.3 \pm 0.9$ \\
\hline & p-bromo-L-Phe & n.d. ${ }^{\mathrm{c}}$ & n.d. ${ }^{\mathrm{c}}$ & $250 \pm 90$ \\
\hline & $p$-iodo-L-Phe & n.d. ${ }^{\mathrm{c}}$ & n.d. ${ }^{\mathrm{c}}$ & $72 \pm 32^{d}$ \\
\hline & $p$-benzoyl-L-Phe & n.d. ${ }^{\mathrm{c}}$ & n.d. ${ }^{c}$ & $0.35 \pm 0.10$ \\
\hline \multirow[t]{5}{*}{ W227S } & L-Phe & $260 \pm 10$ & $2.6 \pm 0.3$ & $100 \pm 20$ \\
\hline & $O$-propargyl-L-Tyr & $325 \pm 4$ & $0.5 \pm 0.1$ & $690 \pm 160$ \\
\hline & p-bromo-L-Phe & $350 \pm 20$ & $0.058 \pm 0.002$ & $6,000 \pm 400$ \\
\hline & $p$-iodo-L-Phe & $380 \pm 50$ & $0.026 \pm 0.003$ & $15,000 \pm 2000$ \\
\hline & $p$-benzoyl-L-Phe & $190 \pm 20$ & $1.6 \pm 0.5$ & $120 \pm 40$ \\
\hline
\end{tabular}

${ }^{\text {a }}$ Values represent the average \pm s.d. of two biological replicas if not stated otherwise.

${ }^{\mathrm{b}}$ Values are from reference 2 .

${ }^{\mathrm{c}}$ n.d. $=$ not determined due to the absence of substrate saturation.

${ }^{d}$ Errors are error of fit for a single experiment. 
Table S2. LC-HRMS analysis. Summary of tyrocidine analogs produced by in vitro reactions with the reprogrammed synthetase $\mathrm{W} 227 \mathrm{~S} \mathrm{TycA} / \mathrm{TycB} / \mathrm{TycC}$ when supplemented with the indicated amino acids.

\begin{tabular}{lccccc}
\hline $\begin{array}{l}\text { supplemented } \\
\text { amino acid }\end{array}$ & $\begin{array}{c}\text { retention } \\
\text { time (min) }\end{array}$ & $\begin{array}{c}\text { relative } \\
\text { intensity }\end{array}$ & compound & $\begin{array}{l}\text { calculated } \\
{[\mathbf{M}+\mathbf{H}]^{+}}\end{array}$ & $\begin{array}{l}\text { found } \\
{[\mathbf{M}+\mathbf{H}]^{+}}\end{array}$ \\
\hline L-Phe & 4.23 & 0.87 & $\mathbf{6}$ & 1286.6568 & 1286.6556 \\
& 4.48 & 1.00 & $\mathbf{1}$ & 1270.6619 & 1270.6597 \\
\hline -propargyl-L-Tyr $^{\text {a }}$ & 4.23 & 0.66 & $\mathbf{6}$ & 1286.6568 & 1286.6561 \\
& 4.48 & 0.50 & $\mathbf{1}$ & 1270.6619 & 1270.6629 \\
& 4.52 & 1.00 & $\mathbf{2}$ & 1324.6725 & 1324.6708 \\
\hline$p$-bromo-L-Phe ${ }^{\text {a }}$ & 4.23 & 0.04 & $\mathbf{6}$ & 1286.6568 & 1286.6581 \\
& 4.48 & 0.02 & $\mathbf{1}$ & 1270.6619 & 1270.6631 \\
& 4.65 & 1.00 & $\mathbf{3}$ & 1350.5723 & 1350.5718 \\
\hline$p$-iodo-L-Phe ${ }^{\text {a }}$ & 4.93 & 0.12 & + & 1428.4809 & 1428.4838 \\
\hline & 4.23 & 0.02 & $\mathbf{6}$ & 1286.6568 & 1286.6584 \\
& 4.48 & 0.02 & $\mathbf{1}$ & 1270.6619 & 1270.6635 \\
& 4.73 & 1.00 & $\mathbf{4}$ & 1396.5585 & 1396.5553 \\
\hline$p$-benzoyl-L-Phe ${ }^{\text {a }}$ & 4.23 & 1.00 & $\mathbf{6}$ & 1286.6568 & 1286.6564 \\
& 4.48 & 0.65 & $\mathbf{1}$ & 1270.6619 & 1270.6621 \\
& 4.65 & 0.05 & $\mathbf{5}$ & 1374.6881 & 1374.6891 \\
\hline
\end{tabular}

$\$$ indicates a tyrocidine analog with two Phe replaced by the respective functionalized amino acid.

${ }^{a}$ The DKP formed between the supplemented amino acid and Pro seen in the chromatograms (Figure 3B) were identified by LC-MS. 
Table S3. LC-HRMS analysis. Summary of tyrocidine analogs produced by in vitro reactions with the reprogrammed synthetase TycA/W2742S TycB/TycC when supplemented with the indicated amino acids.

\begin{tabular}{lccccc}
\hline $\begin{array}{l}\text { supplemented } \\
\text { amino acid }\end{array}$ & $\begin{array}{c}\text { retention time } \\
(\mathbf{m i n})\end{array}$ & $\begin{array}{c}\text { relative } \\
\text { intensity }\end{array}$ & compound & $\begin{array}{l}\text { calculated } \\
{[\mathbf{M}+\mathbf{H}]^{+}}\end{array}$ & $\begin{array}{l}\text { found } \\
{[\mathbf{M}+\mathbf{H}]^{+}}\end{array}$ \\
\hline L-Phe & 4.12 & 0.13 & $\mathbf{1 1}$ & 1286.6556 & 1286.6574 \\
& 4.49 & 1.00 & $\mathbf{1}$ & 1270.6597 & 1270.6572 \\
\hline O-propargyl-L-Tyr & 4.12 & 0.01 & $\mathbf{1 1}$ & 1286.6561 & 1286.6579 \\
& 4.39 & 1.00 & $\mathbf{7}$ & 1324.6708 & 1324.6687 \\
\hline$p$-bromo-Phe & 4.48 & 0.06 & $\mathbf{1}$ & 1270.6629 & 1270.6633 \\
\hline$p$-iodo-Phe & 4.48 & 0.01 & $\mathbf{1}$ & 1270.6631 & 1270.6632 \\
& 4.64 & 1.00 & $\mathbf{8}$ & 1350.5718 & 1350.571 \\
\hline$p$-benzoyl-Phe & 4.92 & 0.13 & + & 1428.4838 & 1428.4831 \\
\hline & 4.68 & 1.00 & $\mathbf{9}$ & 1396.5553 & 1396.5554 \\
& 4.07 & 0.11 & + & 1522.4565 & 1522.4559 \\
\hline 4.48 & 0.07 & 1.00 & $\mathbf{1 0}$ & 1374.6891 & 1374.6877 \\
& 4.48 & 0.59 & $\mathbf{1}$ & 1270.6621 & 1270.6628 \\
\hline
\end{tabular}

$\$$ indicates a tyrocidine analog with two Phe replaced by the respective functionalized amino acid. 
Table S4. Specificity codes for select homologs of the TycA A domain possessing a delimiting Trp residue.

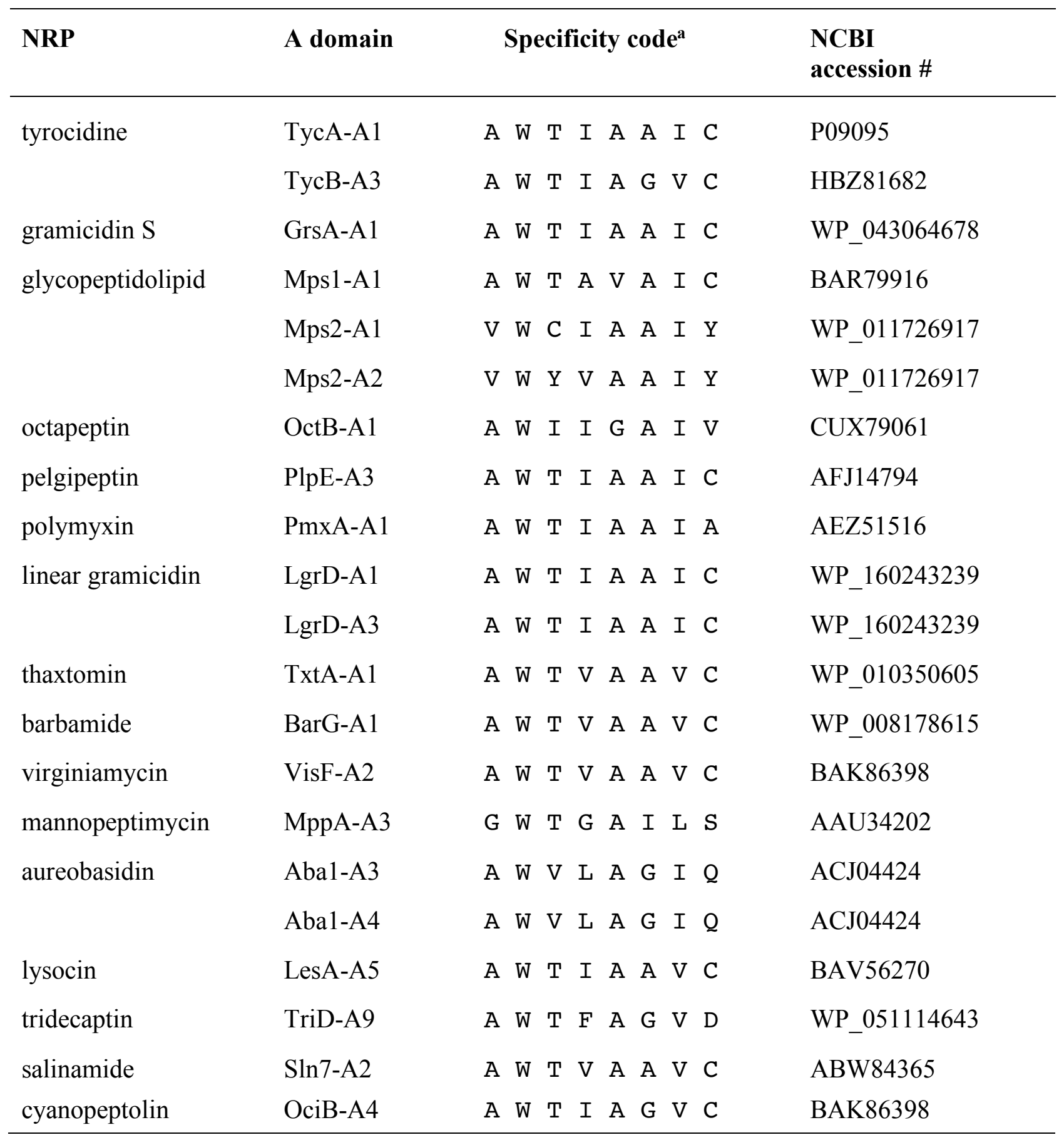

a Amino acids corresponding to the specificity conferring positions 224, 227, 266, 287, 289, 310, 318 and 319 in TycA-A. ${ }^{6,7}$ Position 227 in TycA-A corresponds to position 239 in GrsA-A. 


\section{W227S TycA (residues 1-1088)}

XVANQANLID NKRELEQHAL VPYAQGKSIH QLFEEQAEAF PDRVAIVFEN RRLSYQELNR KANQLARALL EKGVQTDSIV GVMMEKSIEN VIAILAVLKA GGAYVPIDIE YPRDRIQYIL QDSQTKIVLT QKSVSQLVHD VGYSGEVVVL DEEQLDARET ANLHQPSKPT DLAYVIYTSG TTGKPKGTML EHKGIANLQS FFQNSFGVTE QDRIGLFASM SFDASVSEMF MALLSGASLY ILSKQTIHDF AAFEHYLSEN ELTIITLPPT YLTHLTPERI TSLRIMITAG SASSAPLVNK WKDKLRYINA YGPTETSICA TIWEAPSNQL SVQSVPIGKP IQNTHIYIVN EDLQLLPTGS EGELCIGGVG LARGYWNRPD LTAEKFVDNP FVPGEKMYRT GDLAKWLTDG TIEFLGRIDH QVKIRGHRIE LGEIESVLLA HEHITEAVVI AREDQHAGQY LCAYYISQQE ATPAQLRDYA AQKLPAYMLP SYFVKLDKMP LTPNDKIDRK ALPEPDLTAN QSQAAYHPPR TETESILVSI WQNVLGIEKI GIRDNFYSLG GDSIQAIQVV ARLHSYQLKL ETKDLLNYPT IEQVALFVKS TTRKSDQGII AGNVPLTPIQ KWFFGKNFTN TGHWNQSSVL YRPEGFDPKV IQSVMDKIIE HHDALRMVYQ HENGNVVQHN RGLGGQLYDF FSYNLTAQPD VQQAIEAETQ RLHSSMNLQE GPLVKVALFQ TLHGDHLFLA IHHLVVDGIS WRILFEDLAT GYAQALAGQA ISLPEKTDSF QSWSQWLQEY ANEADLLSEI PYWESLESQA KNVSLPKDYE VTDCKQKSVR NMRIRLHPEE TEQLLKHANQ AYQTEINDLL LAALGLAFAE WSKLAQIVIH LEGHGREDII EQANVARTVG WFTSQYPVLL DLKQTAPLSD YIKLTKENMR KIPRKGIGYD ILKHVTLPEN RGSLSFRVQP EVTFNYLGQF DADMRTELFT RSPYSGGNTL GADGKNNLSP ESEVYTALNI TGLIEGGELV LTFSYSSEQY REESIQQLSQ SYQKHLLAII AHCTEKKEVE RTPSDFSVKG LQMEEMDDIF ELLANTLR

A His6-tag is appended to the N-terminus of the protein via an SGRS linker: $\mathrm{X}=$ MHHHHHHSGRS; residue 227 is highlighted in red

\section{Module 3 A, T and E domains of W2742S TycB (residues 2521-3588)}

MLTAAEKQML LVAFNDTHRE YRADQTIQQL FEELAEKMPE HTALVFEEKR MSFRELNERA NQLAAVLREK GVGPAQIVAL LVERSAEMVI ATLATLKAGG AFLPVDPDYP EERIRYMLED SQAKLVVTHA HLLHKVSSQS EVVDVDDPGS YATQTDNLPC ANTPSDLAYI IYTSGTTGKP KGVMLEHKGV ANLQAVFAHH LGVTPQDRAG HFASISFDAS VSDMFGPLLS GATLYVLSRD VINDFQRFAE YVRDNAITFL TLPPTYAIYL EPEQVPSLRT LITAGSASSV ALVDKWKEKV TYVNGYGPTE STVCATLWKA KPDEPVETIT IGKPIQNTKL YIVDDQLQLK APGQMGELCI SGLSLARGYW NRPELTAEKF VDNPFVPGTK MYRTGDLARW LPDGTIEYLG RIDHQVKIRG HRVELGEVES VLLRYDTVKE AAAITHEDDR GQAYLCAYYV AEGEATPAQL RAYMENELPN YMVPAFFIQL EKMPLTPNDK IDRKALPKPN QEENRTEQYA APQTELEQLL AGIWADVLGI KQVGTQDNFF ELGGDSIKAI QVSTRLNASG WTLAMKELFQ YPTIEEAALR VIPNSRESEQ GVVEGEIALT PIQKWFFANN FTDRHHWNQA VMLFREDGFD EGLVRQAFQQ IVEHHDALRM VYKQEDGAIK QINRGLTDER FRFYSYDLKN HANSEARILE LSDQIQSSID LEHGPLVHVA LFATKDGDHL LVAIHHLVVD GVSWRILFED FSSAYSQALH QQEIVLPKKT DSFKDWAAQL QKYADSDELL REVAYWHNLE TTTTTAALPT DFVTADRKQK HTRTLSFALT VPQTENLLRH VHHAYHTEMN DLLLTALGLA VKDWAHTNGV VINLEGHGRE DIQNEMNVTR TIGWFTSQYP VVLDMEKAED LPYQIKQTKE NLRRIPKKGI GYEILRTLTT SQLQPPLAFT LRPEISFNYL GQFESDGKTG GFTFSPLGTG QLFSPESERV FLLDISAMIE DGELRISVGY SRLQYEEKTI ASLADSYRKH LLGIIEHCMA KEEGEYTPSD LGDEELSMEE LENILEWIGS RSHHHHHH

A His6-tag is appended to the C-terminus of the protein via a GSRS linker; residue 2742 is highlighted in red.

\section{Figure S1. Amino acid sequences of the modified tyrocidine synthetases}




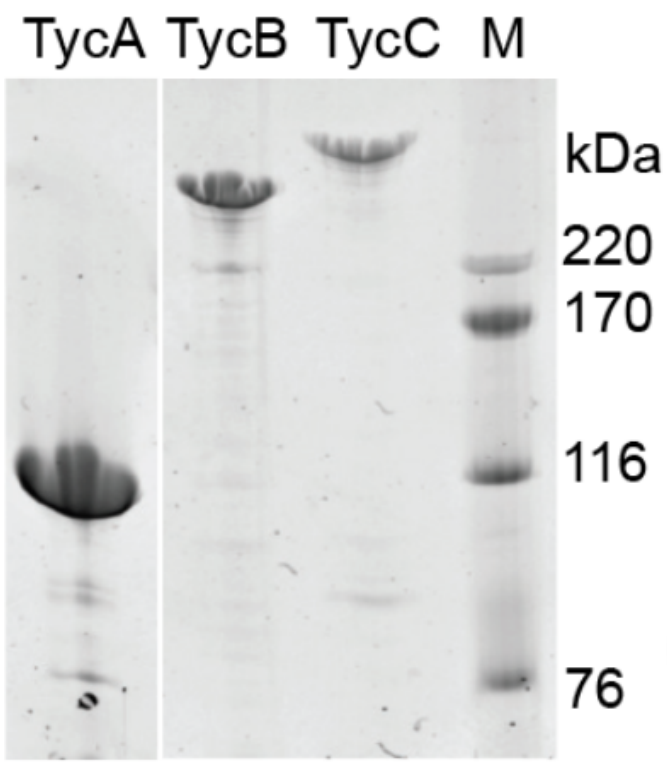

Figure S2. Protein production. 7.5\% SDS-PAGE gels showing purified His 6 -tagged TycA, TycB and TycC produced in E. coli $\mathrm{HM} 0079 ; \mathrm{M}=$ marker 


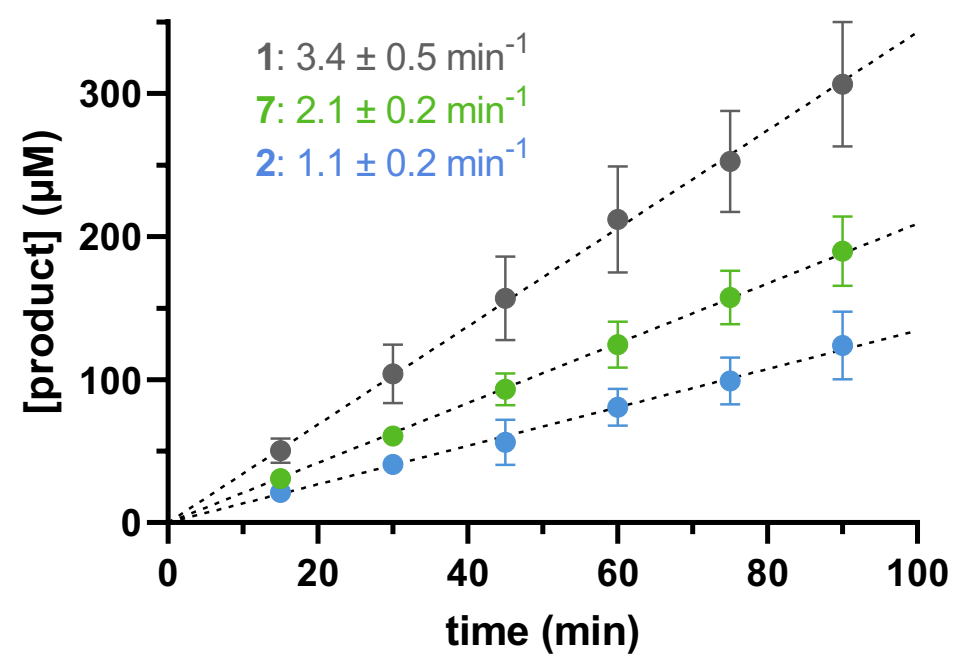

Figure S3. Kinetics for tyrocidine formation. In vitro biosynthesis of 1 (gray), 2 (blue), and 7 (green) by the wildtype synthetase, W227S TycA/TycB/TycC and TycA/W2742S TycB/TycC, respectively, was linear over the first $90 \mathrm{~min}$ and used to calculate $\mathrm{k}_{\mathrm{obs}}$ values. As shown in Figure S4, W227S TycA/TycB/TycC produced a $\sim 3: 1$ mixture of $\mathbf{2}$ and $\mathbf{1}$ and the data were corrected accordingly. 


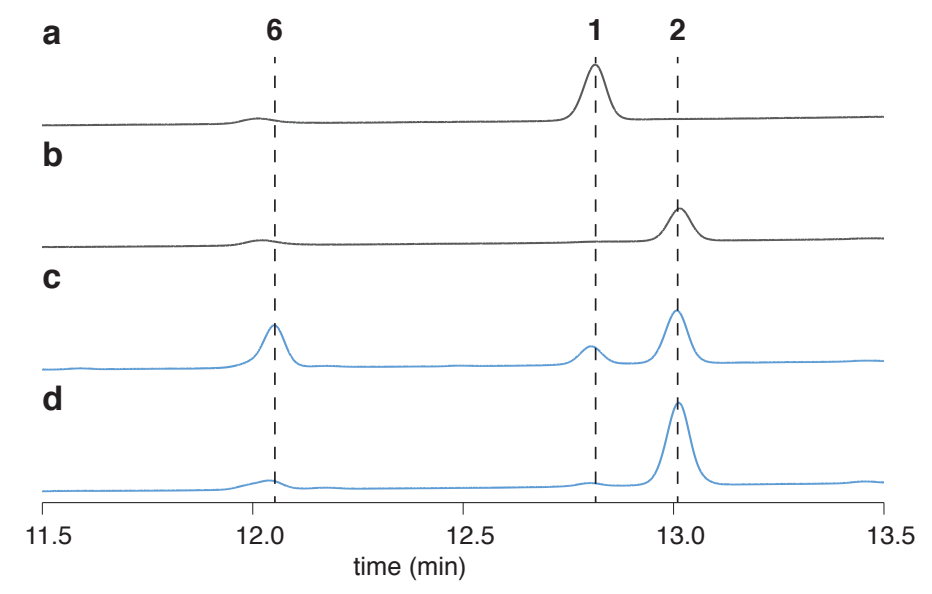

Figure S4. Selectivity of W227S TycA. HPLC chromatograms of authentic standards of (a) tyrocidine A (1) and (b) 2 and the products of in vitro reactions with the W227S TycA/TycB/TycC synthetase supplemented with (c) $2 \mathrm{mM}$ or (d) $20 \mathrm{mM} O$-propargyl-L-Tyr, respectively. Tyrocidines $\mathbf{1}$ or $\mathbf{6}$ are formed as side product by incorporation of L-Phe or L-Tyr at position 1. The reactions and authentic standards were injected onto a Reprospher 100 Phenyl-hexyl column to achieve baseline separation of $\mathbf{1}$ and $\mathbf{2}$; note that the column and conditions differ from those described in Figure 3 of the main text. 

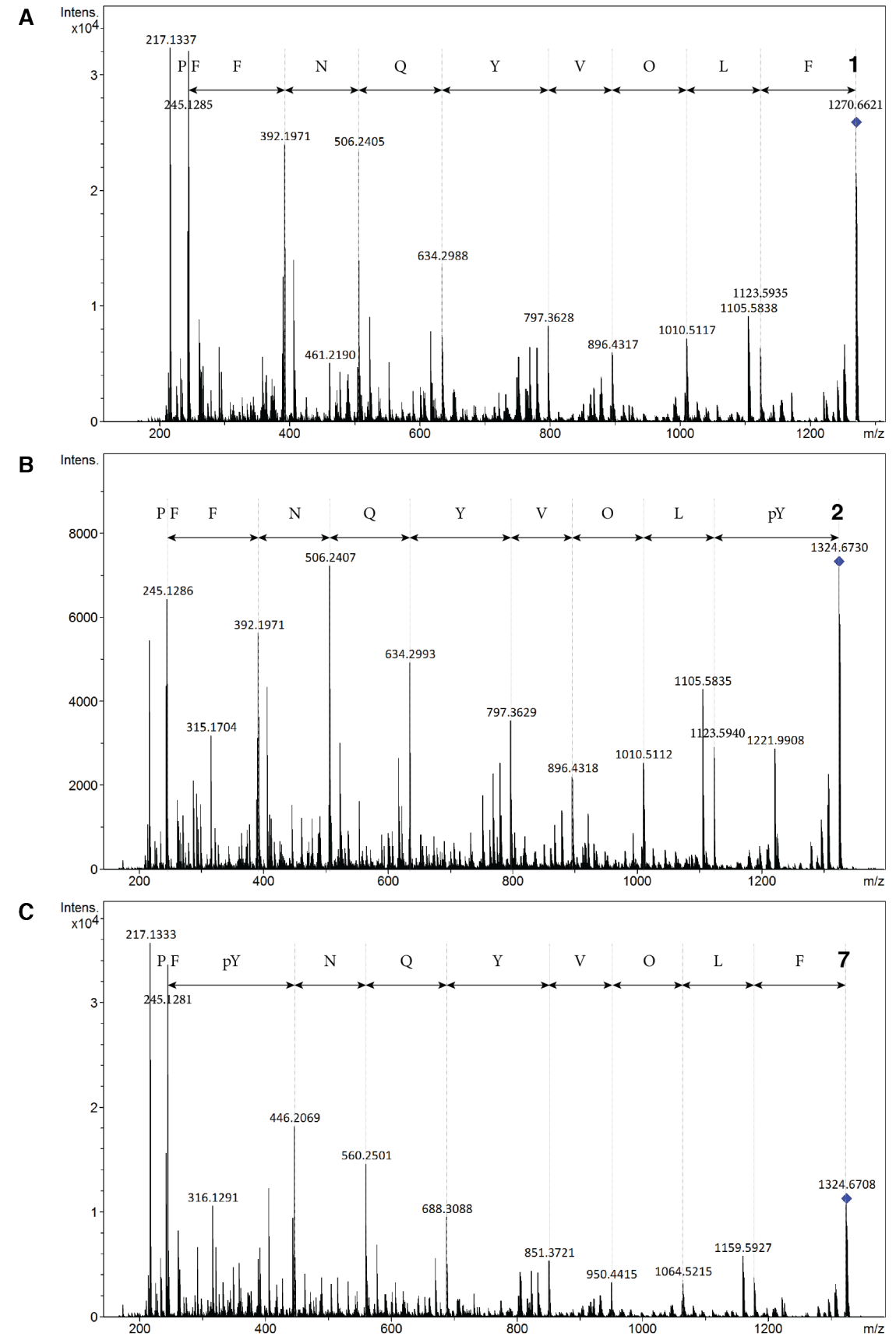

Figure S5. MS/MS analysis of (A) tyrocidine A (1), (B) 2, and (C) 7. The found b-ion series and respective amino acid sequence is shown for each compound. $\mathrm{O}=$ ornithine, $\mathrm{pY}=O$-propargyltyrosine. 


\section{NMR spectra}

Tyrocidine A (1): ${ }^{1} \mathrm{H}-\mathrm{NMR}$ (DMSO-d6)
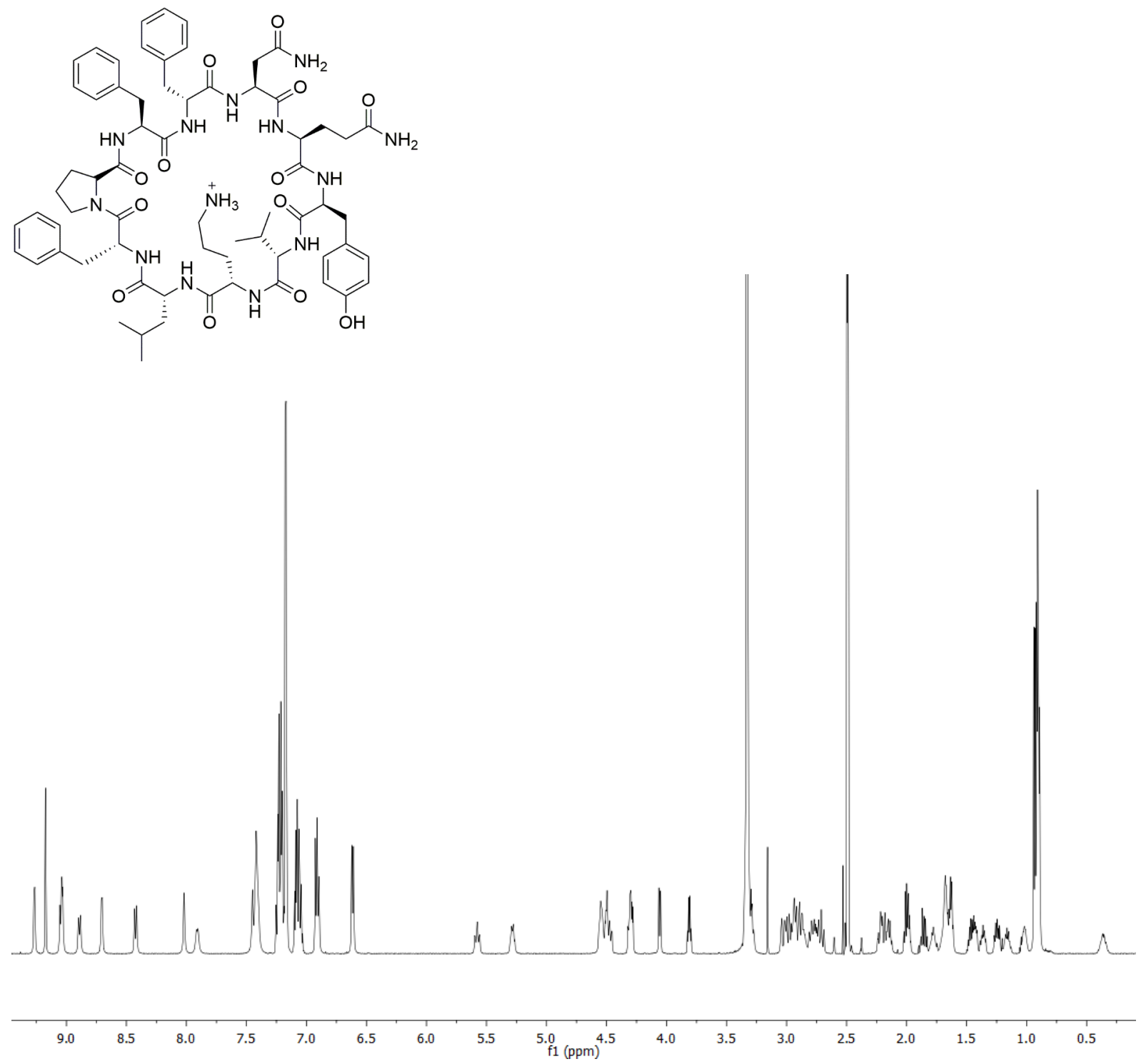
Tyrocidine A (1): ${ }^{13} \mathrm{C}-\mathrm{NMR}$ (DMSO- $d_{6}$ )
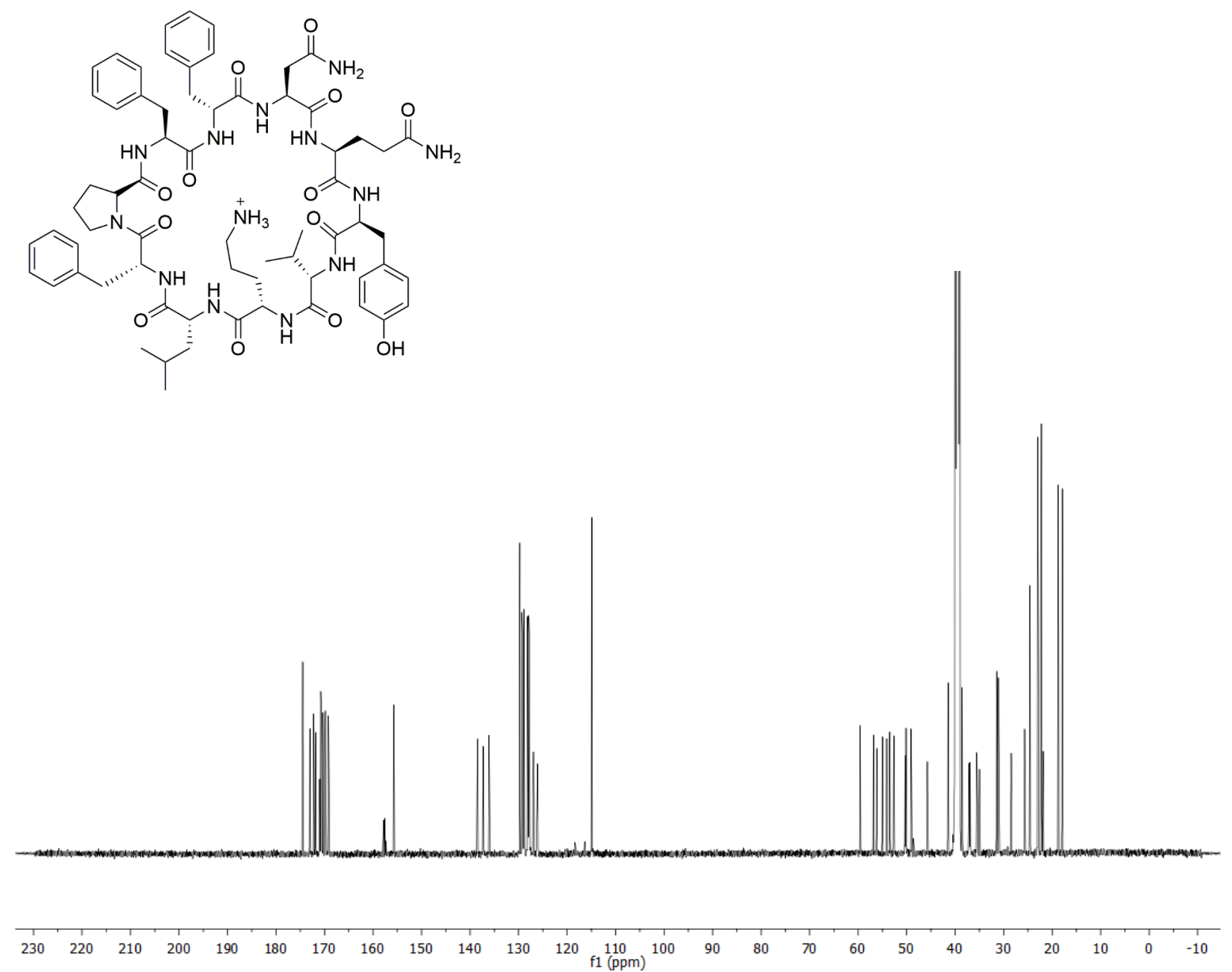
Tyrocidine A (1): HSQC (DMSO- $d_{6}$ )
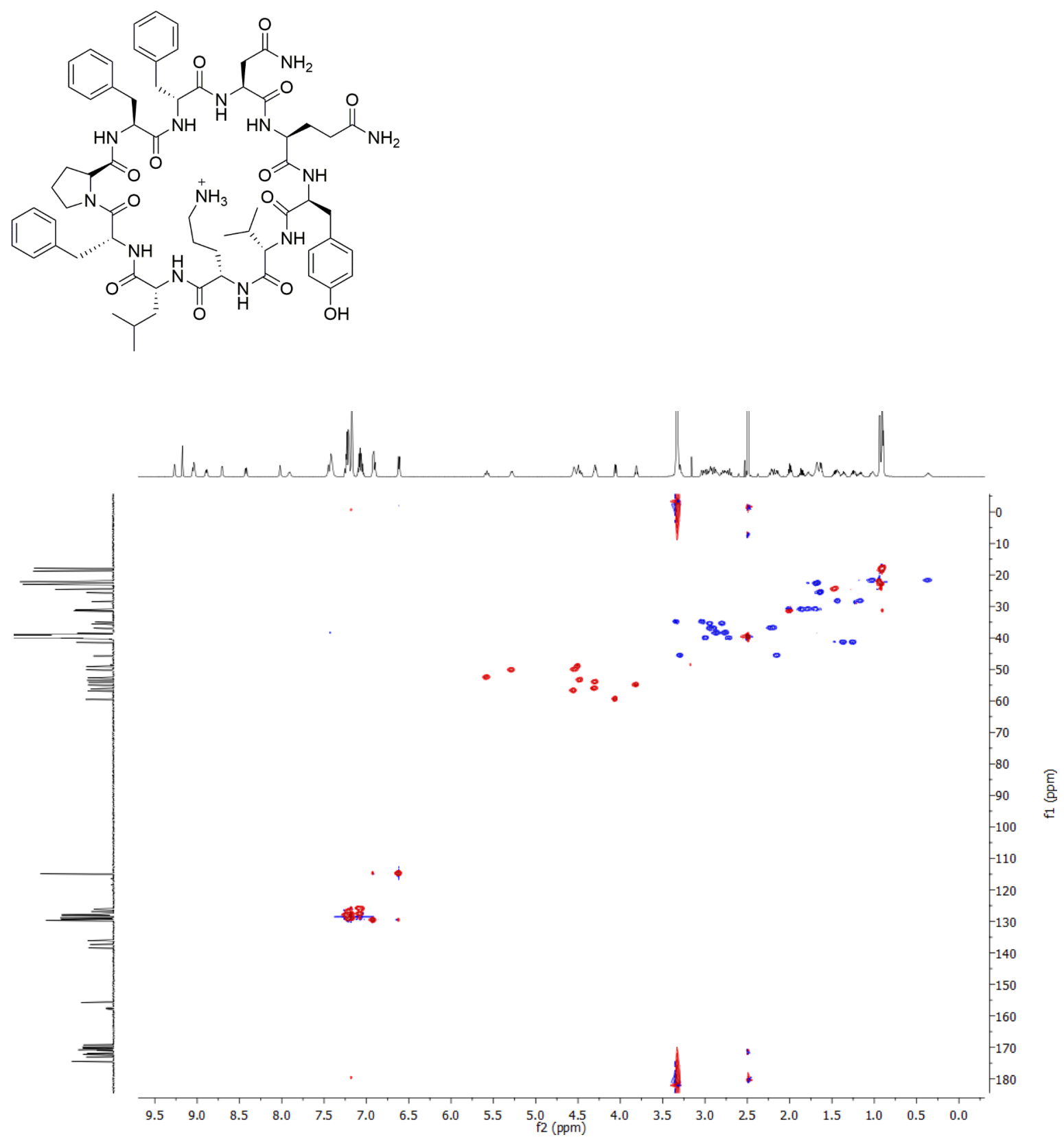
Tyrocidine A (1): HMBC (DMSO- $d_{6}$ )

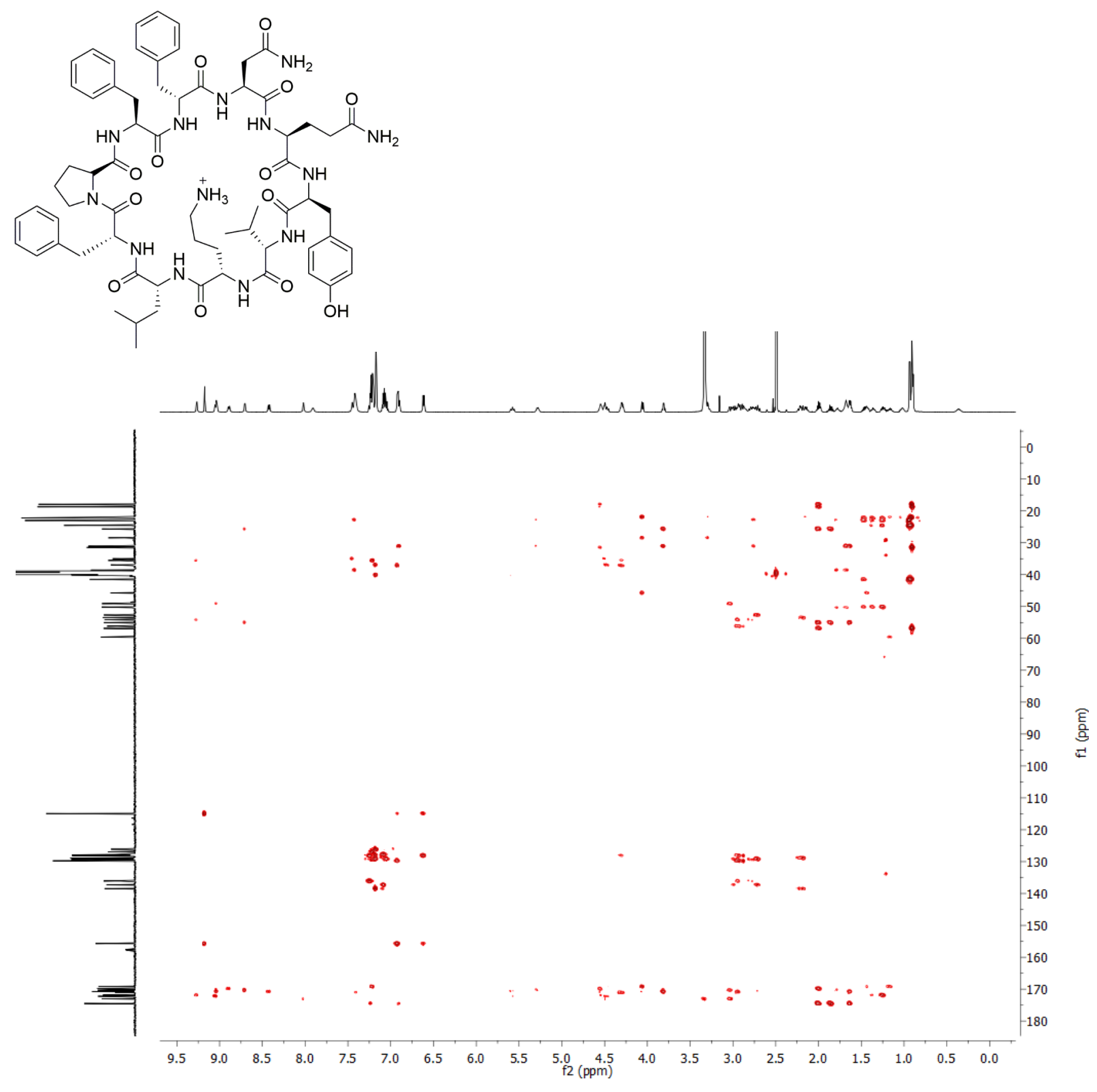


Tyrocidine A (1): ${ }^{15} \mathrm{~N}-\mathrm{HSQC}$ (DMSO- $d_{6}$ )
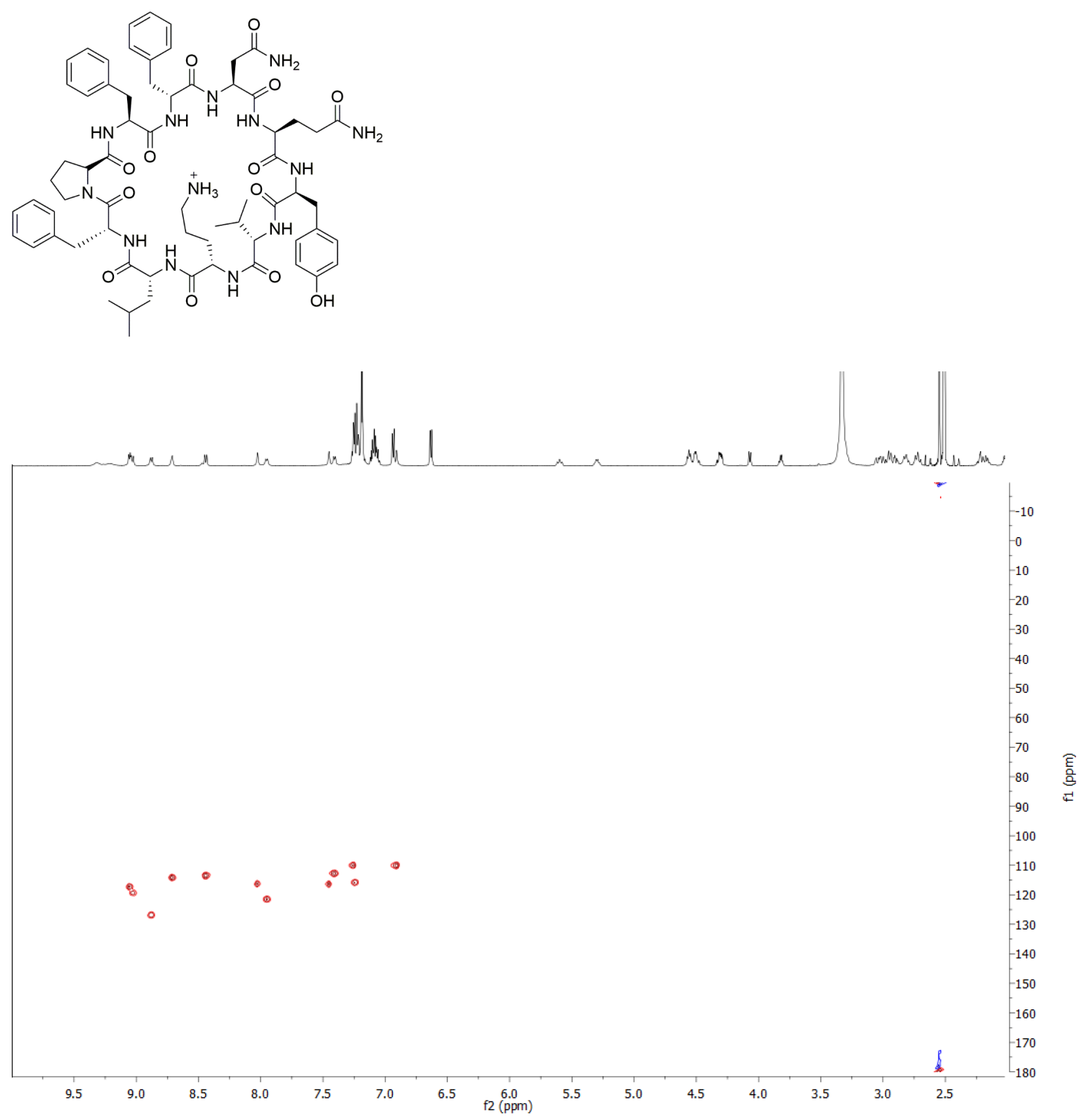
Propargylated tyrocidine A (2): ${ }^{1} \mathrm{H}-\mathrm{NMR}$ (DMSO- $d 6$ )
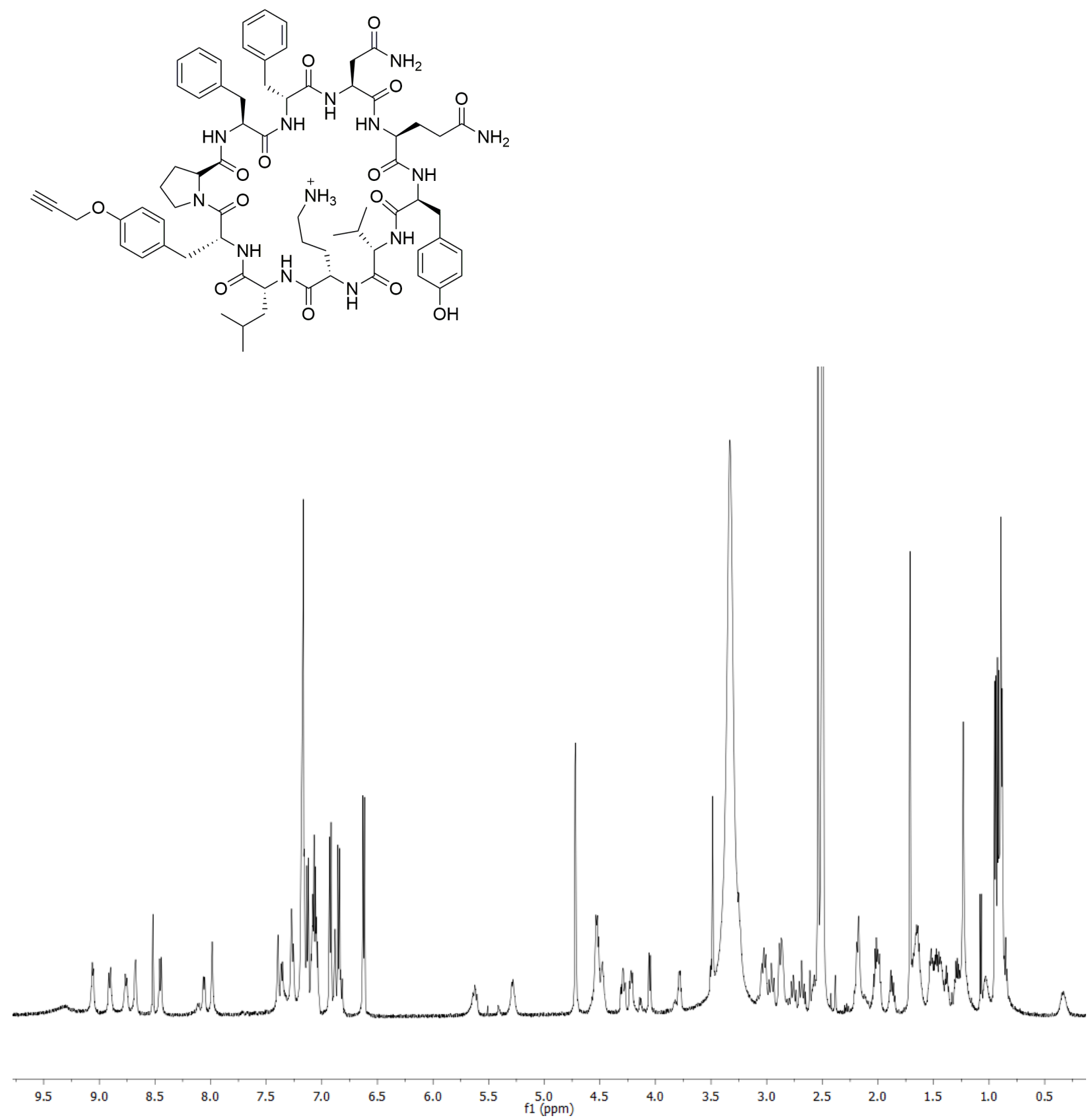
Propargylated tyrocidine A (2): ${ }^{13} \mathrm{C}-\mathrm{NMR}$ (DMSO- $d_{6}$ )

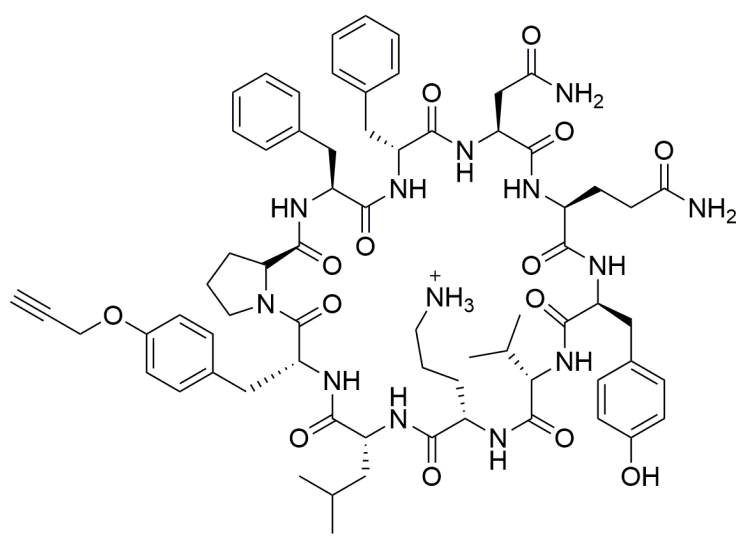

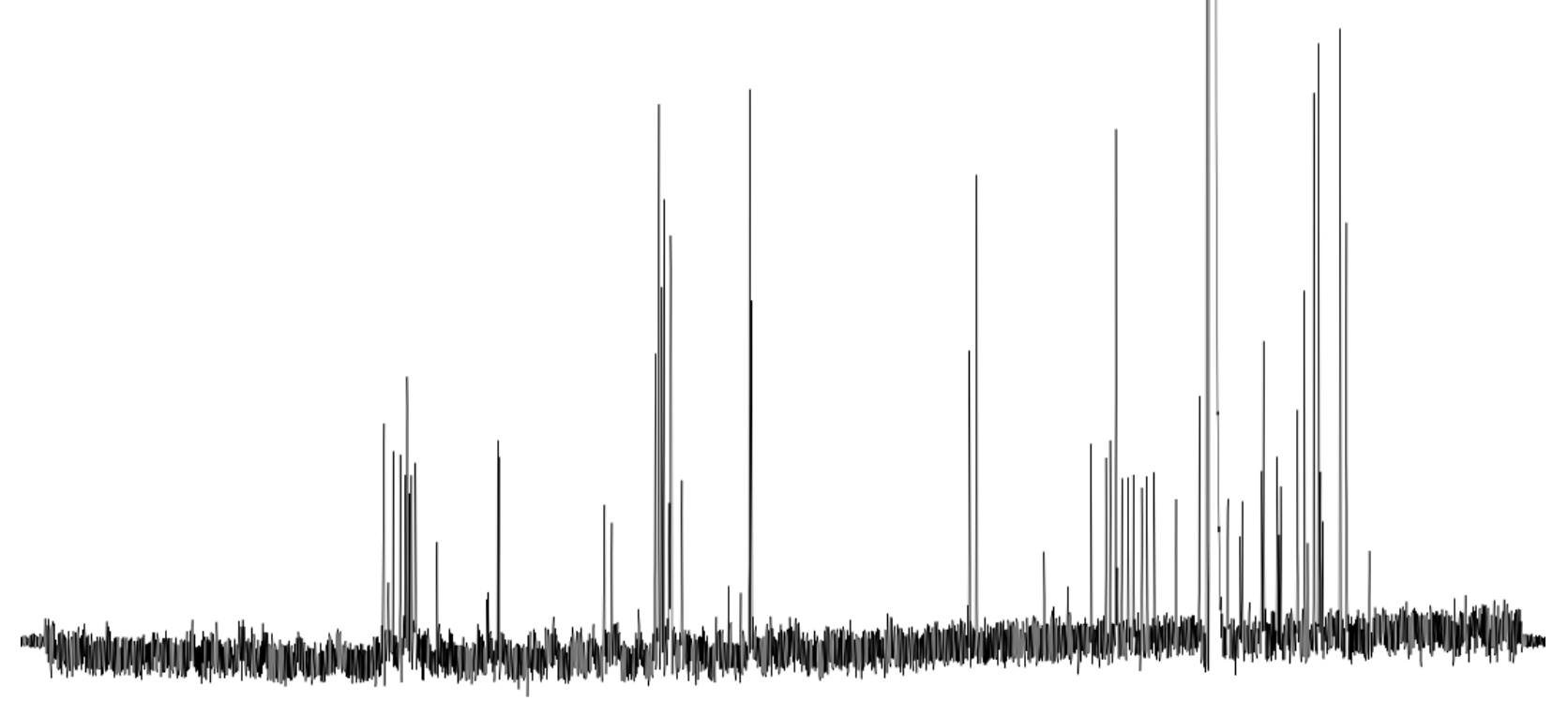

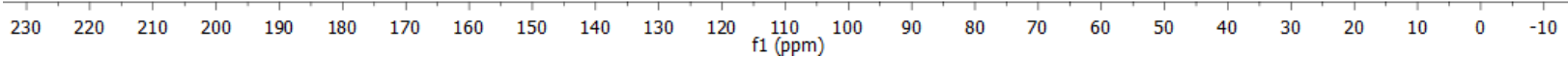


Propargylated tyrocidine A (2): HSQC (DMSO- $d_{6}$ )
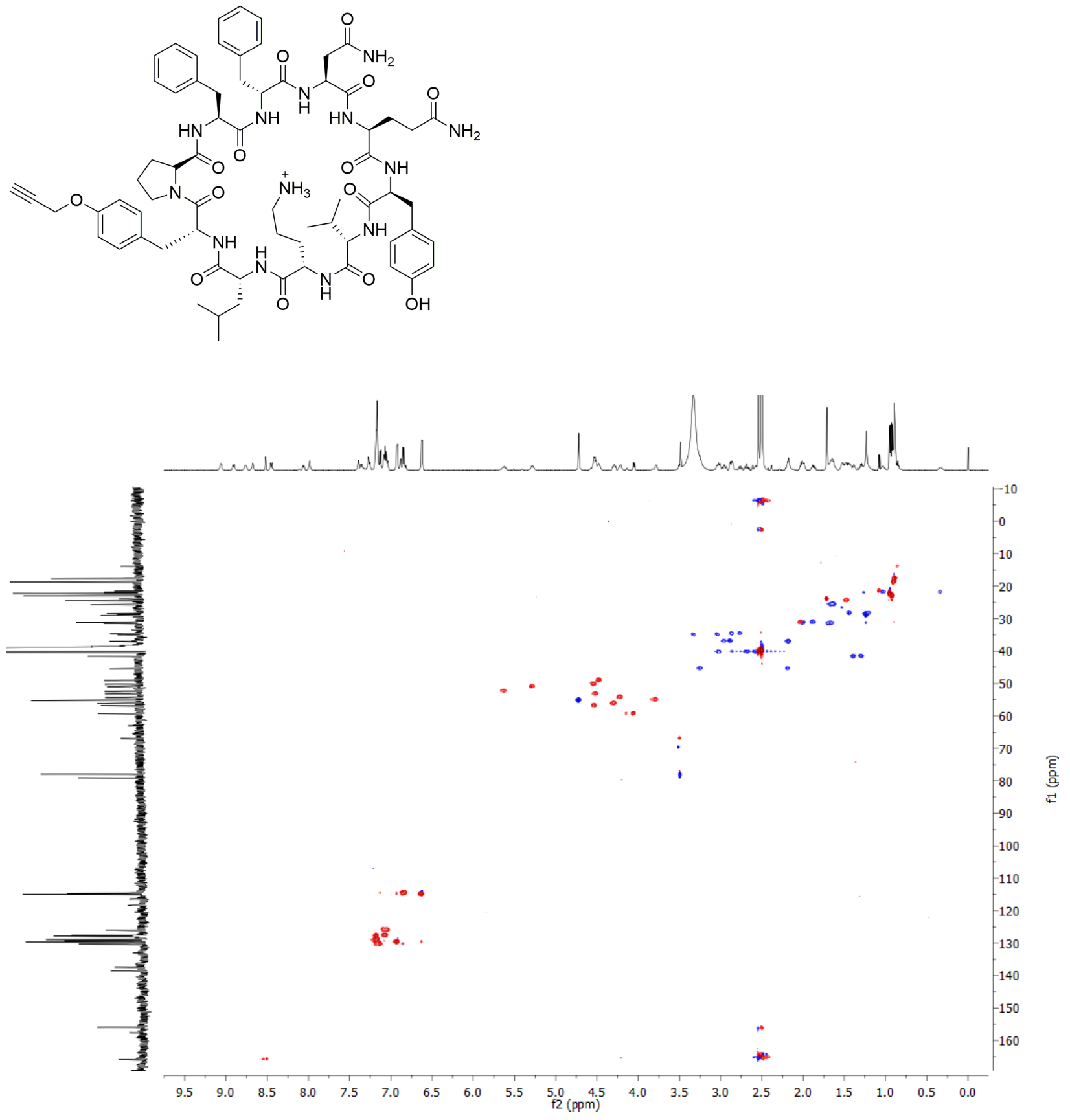
Propargylated tyrocidine A (2): HMBC (DMSO- $d_{6}$ )
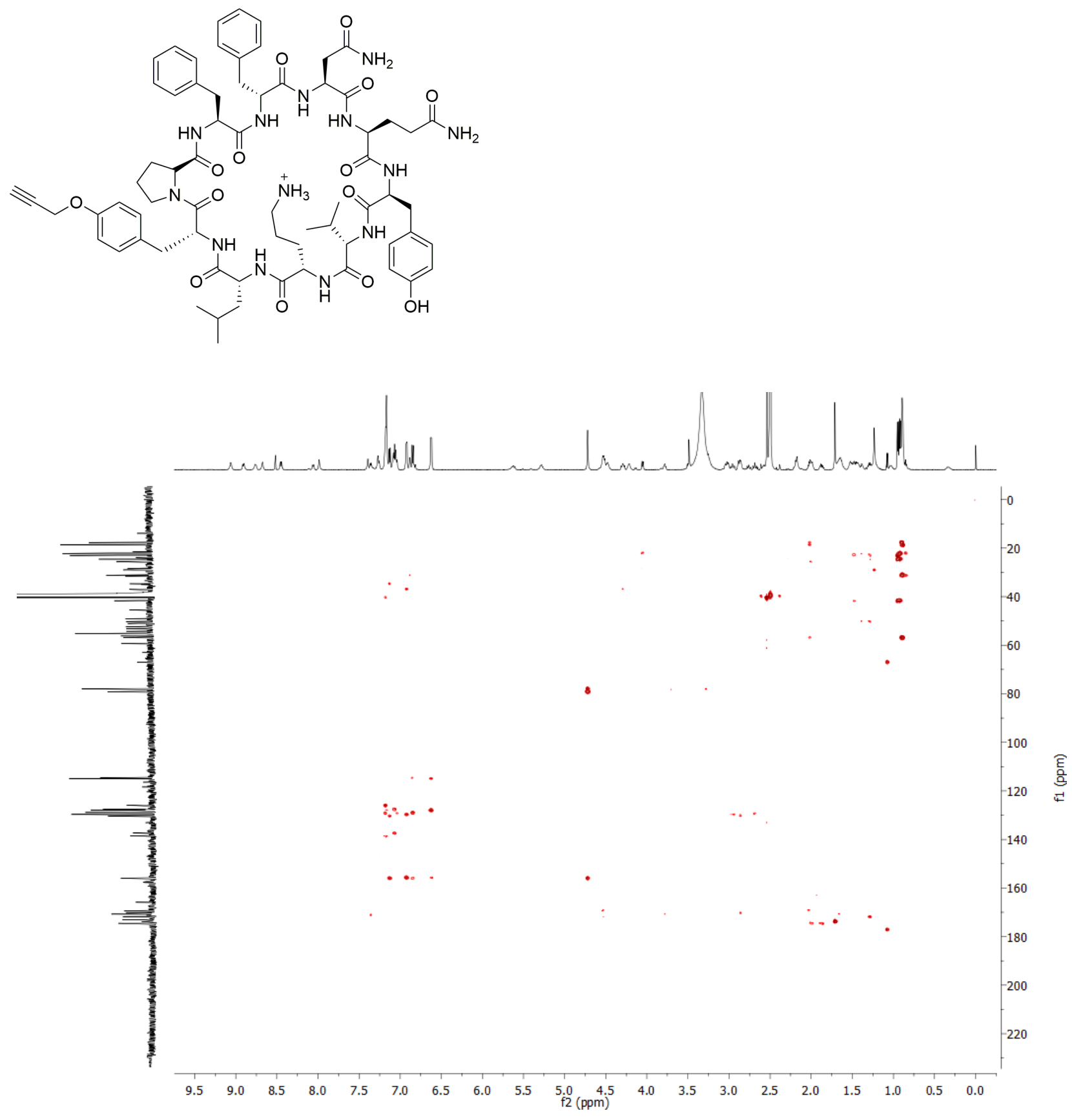
Propargylated tyrocidine A (2): ${ }^{15} \mathrm{~N}-\mathrm{HSQC}$ (DMSO- $d_{6}$ )
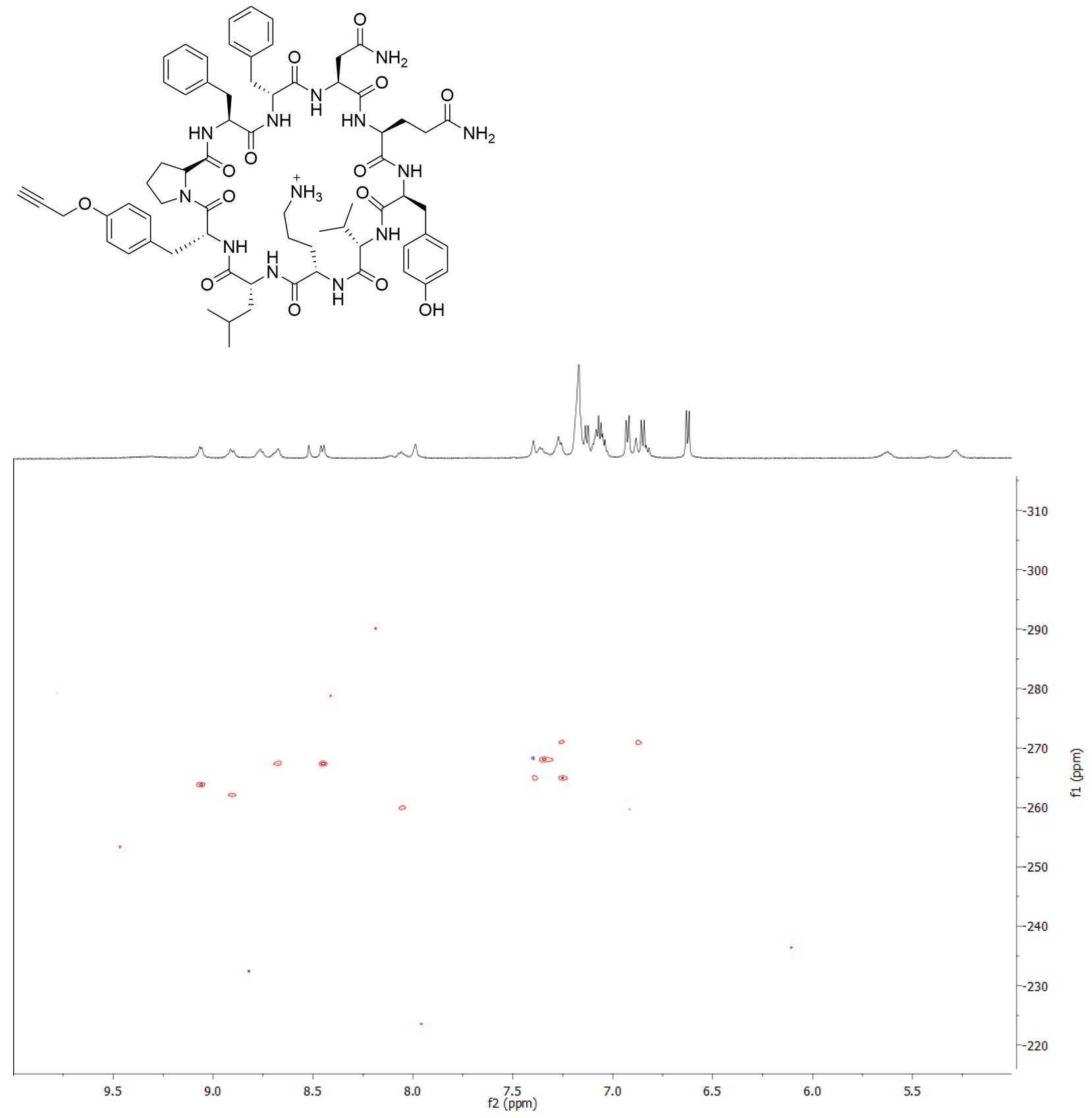
Propargylated tyrocidine A (7): ${ }^{1} \mathrm{H}-\mathrm{NMR}$ (DMSO- $d 6$ )
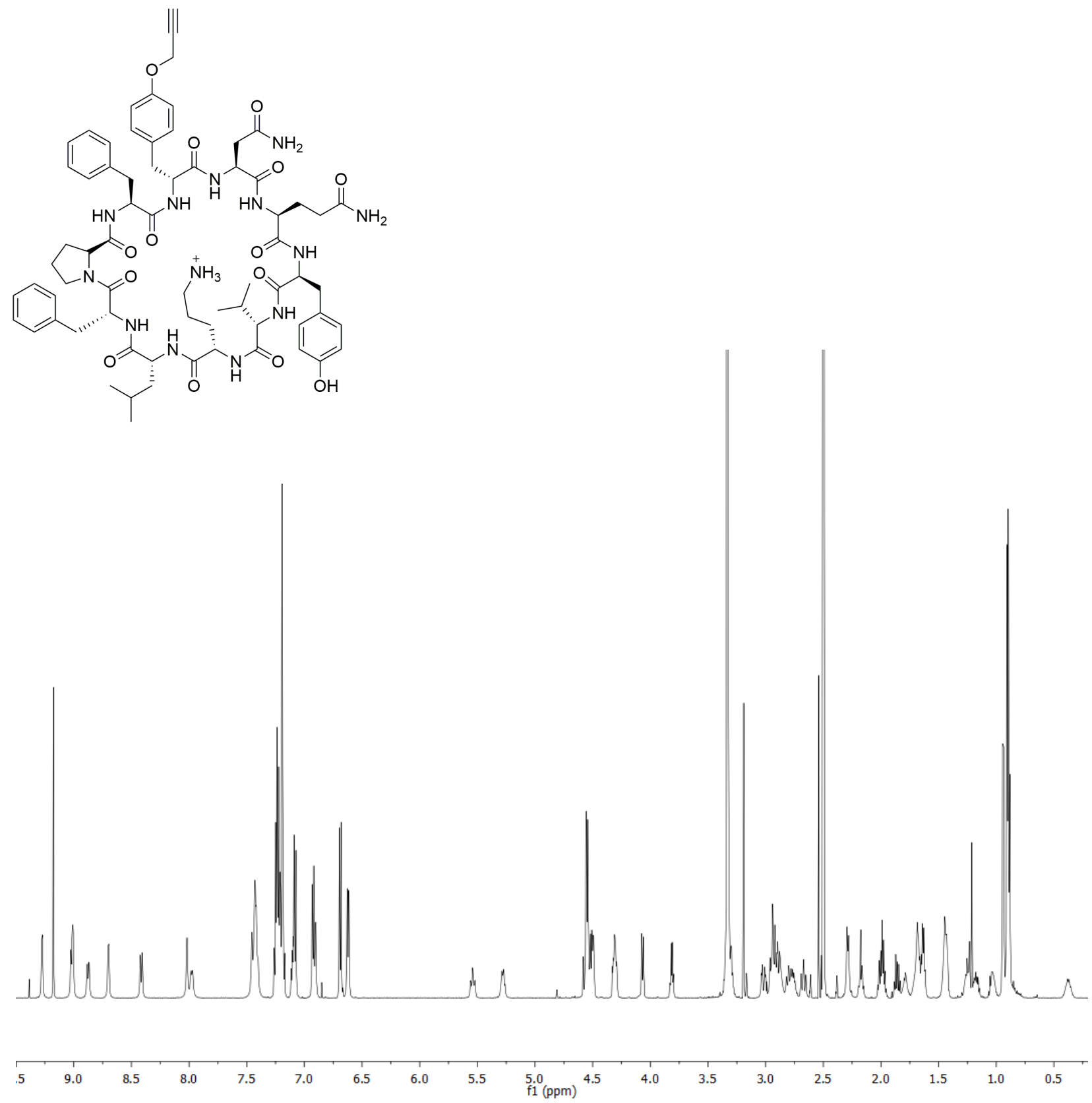
Propargylated tyrocidine A (7): ${ }^{13} \mathrm{C}-\mathrm{NMR}$ (DMSO- $d_{6}$ )
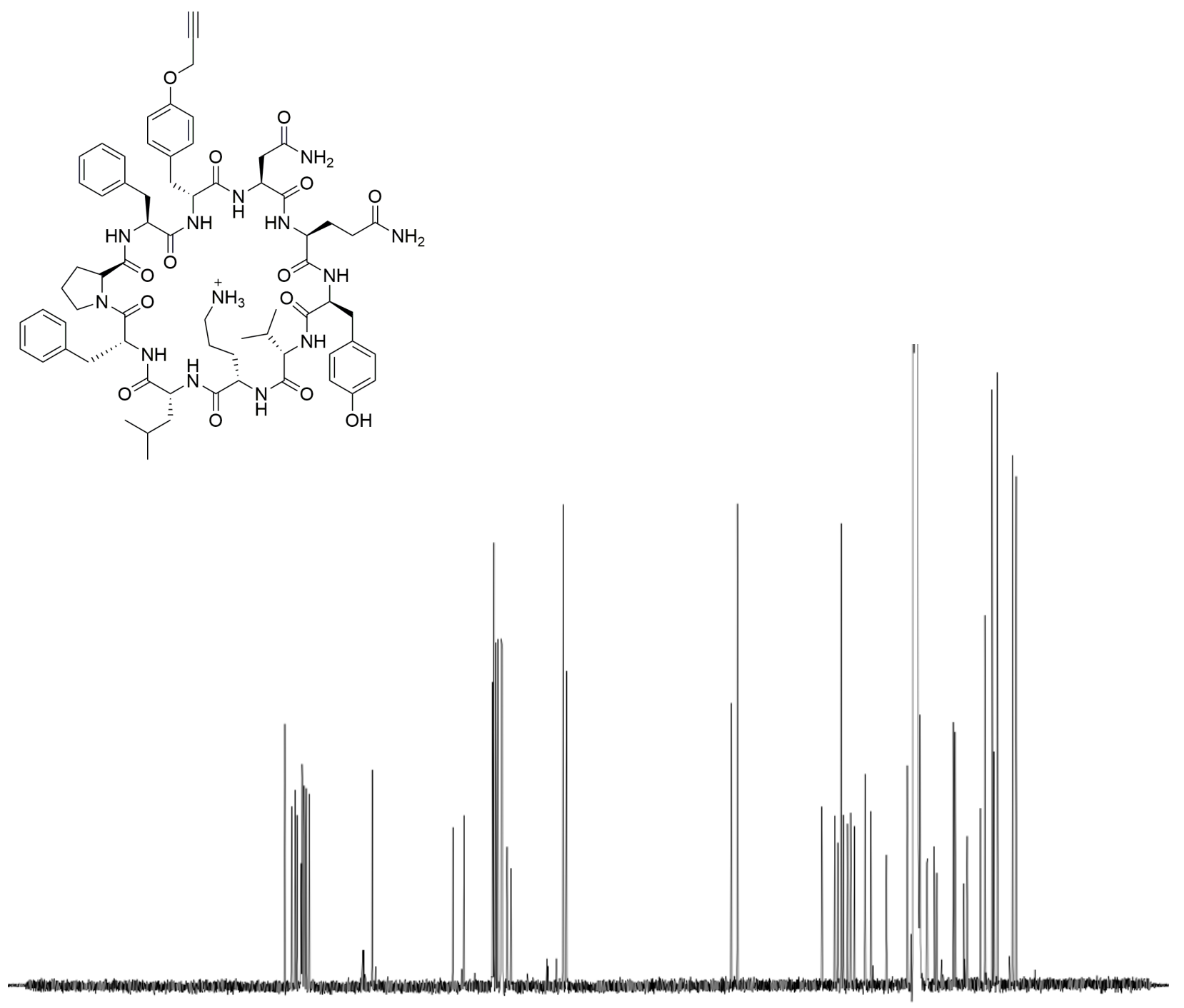

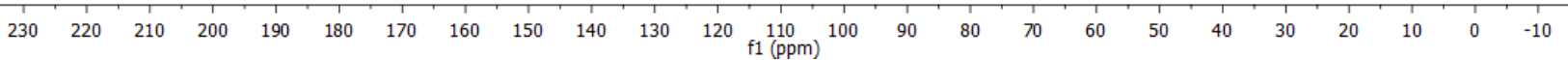


Propargylated tyrocidine A (7): HSQC (DMSO- $d_{6}$ )

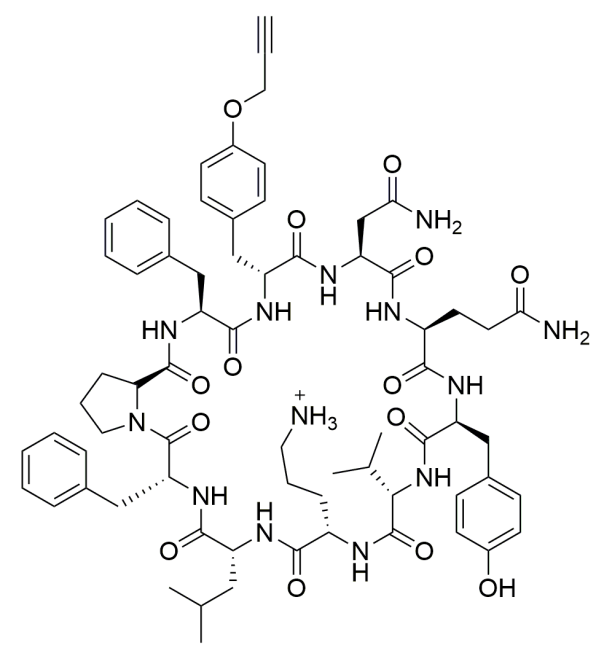

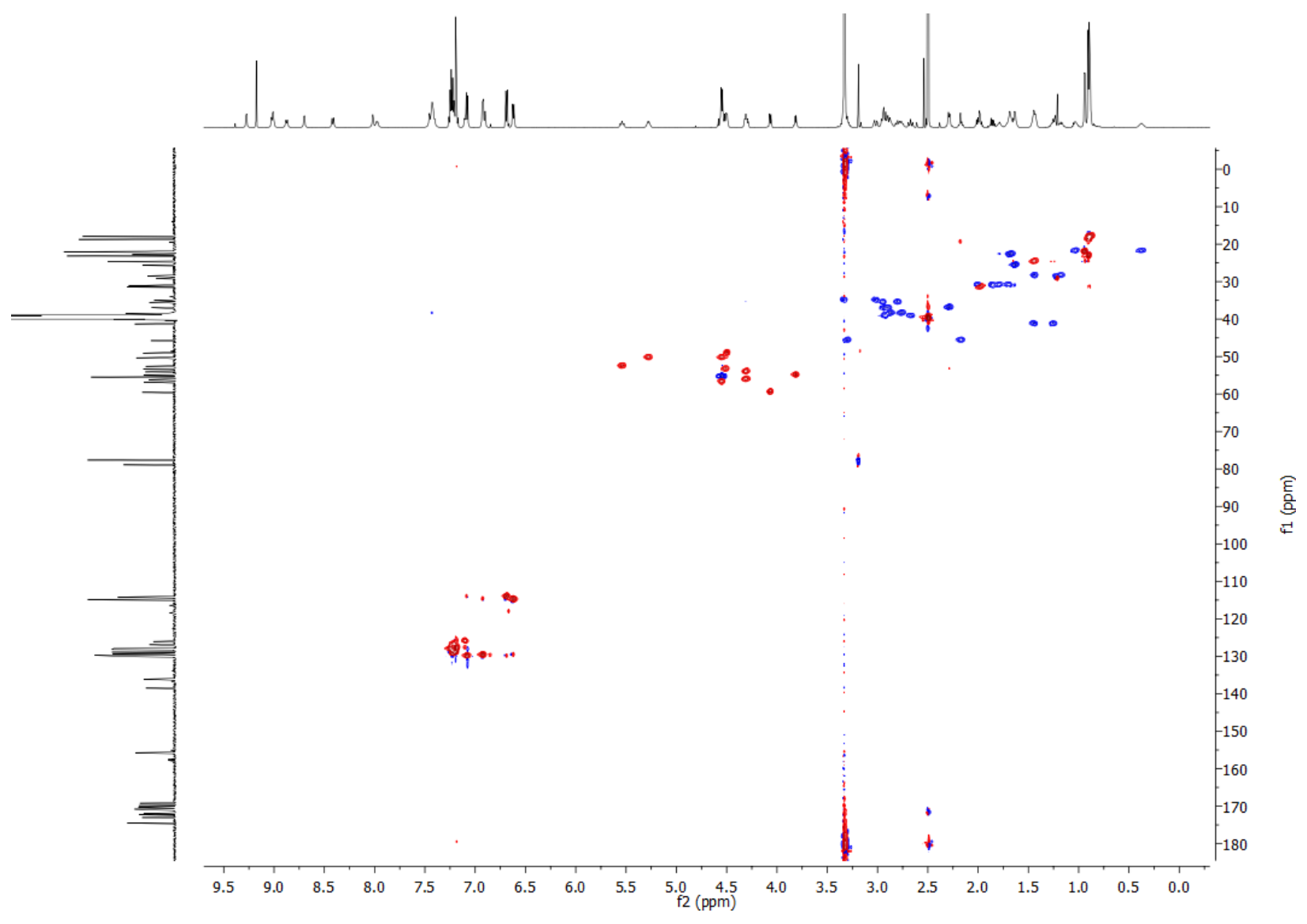


Propargylated tyrocidine A (7): HMBC (DMSO- $d_{6}$ )

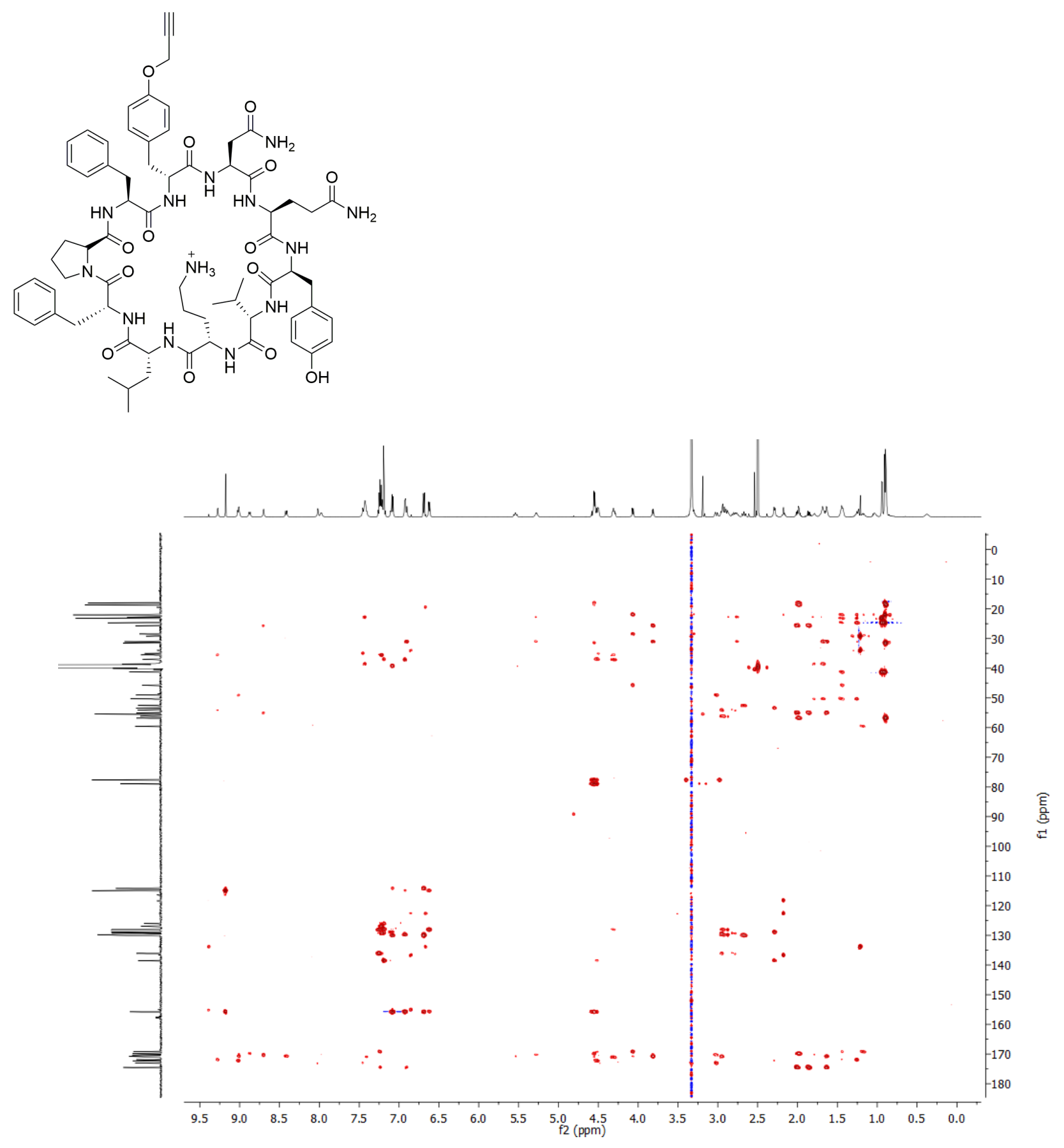


Propargylated tyrocidine A (7): ${ }^{15} \mathrm{~N}-\mathrm{HSQC}$ (DMSO- $d_{6}$ )
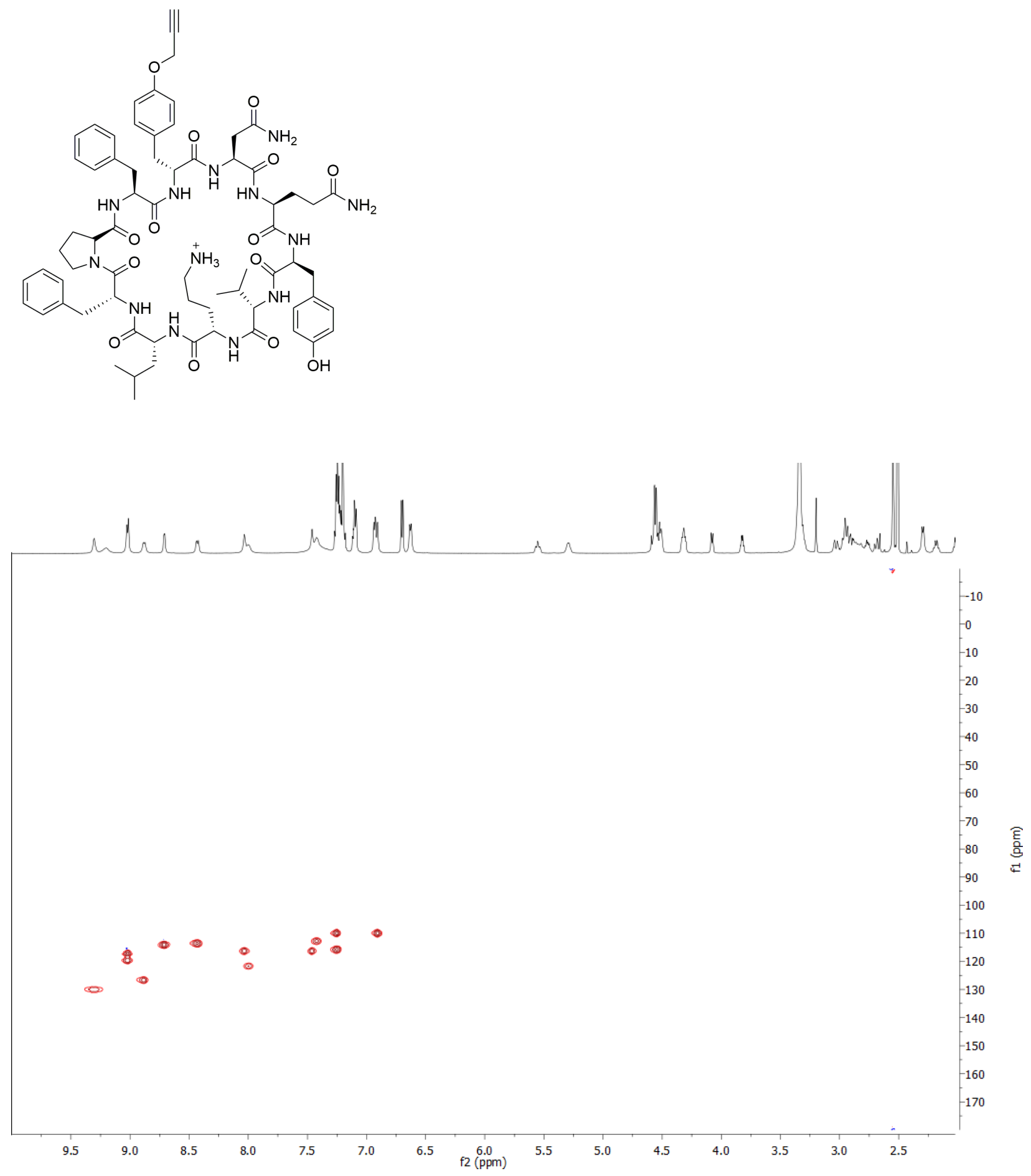
TAMRA-modified tyrocidine A (14): ${ }^{1} \mathrm{H}-\mathrm{NMR}$ (DMSO- $d 6$ )
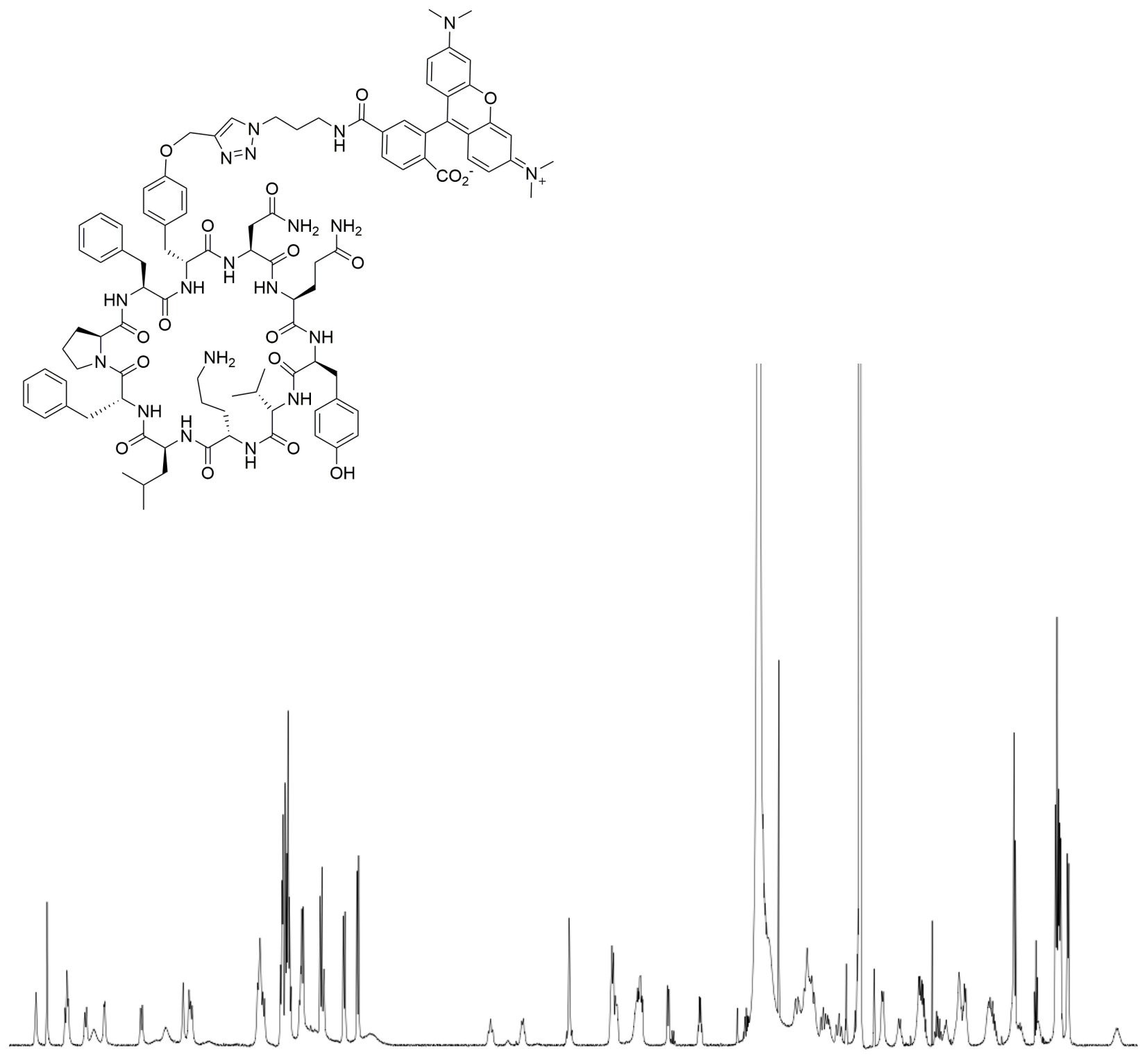

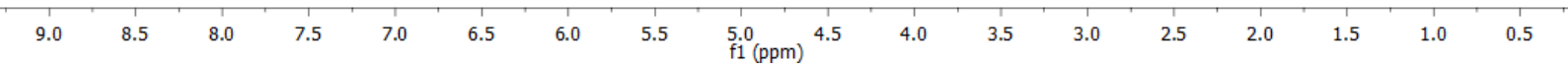


TAMRA-modified tyrocidine A (14): ${ }^{13} \mathrm{C}-\mathrm{NMR}$ (DMSO- $d_{6}$ )
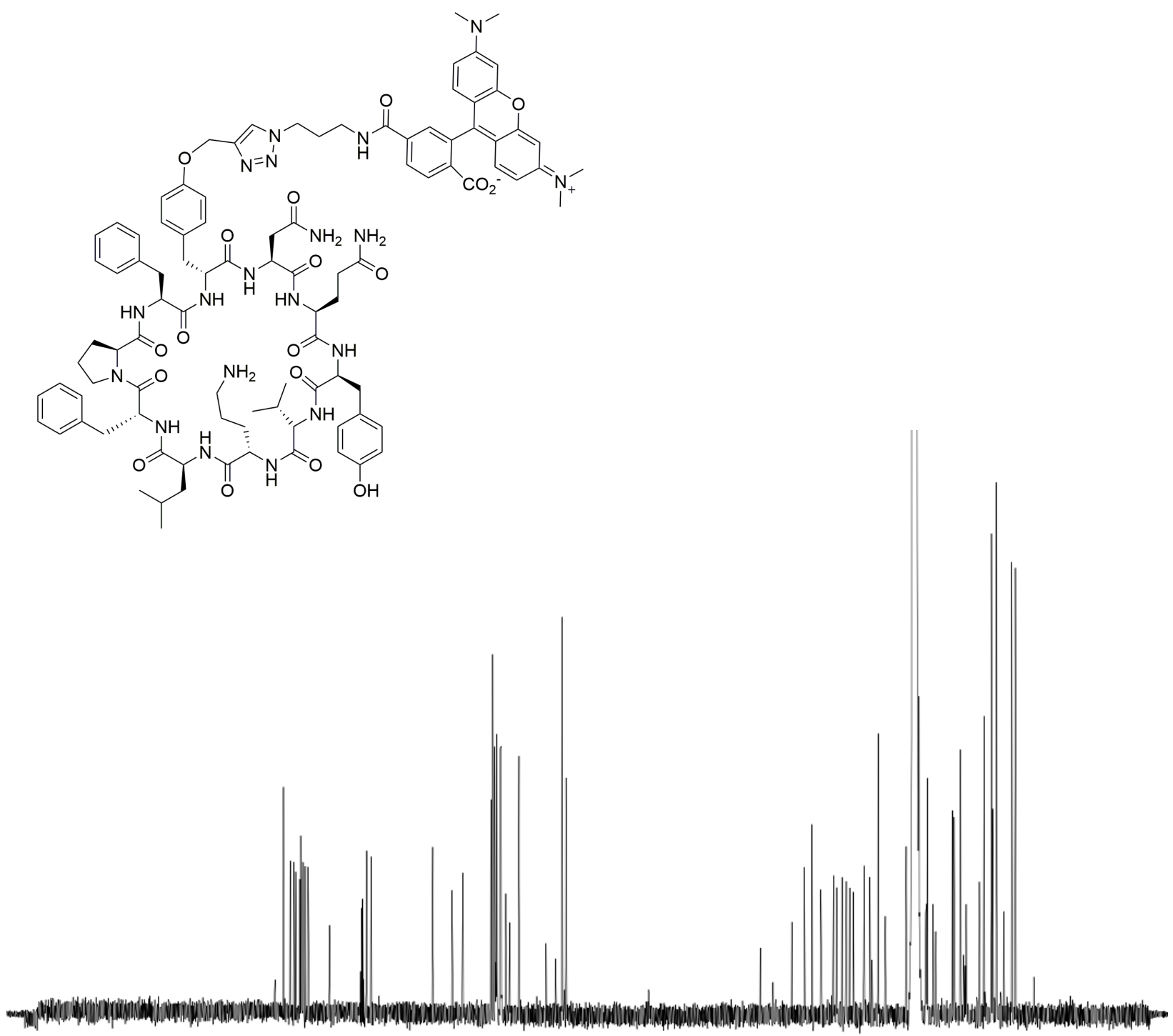

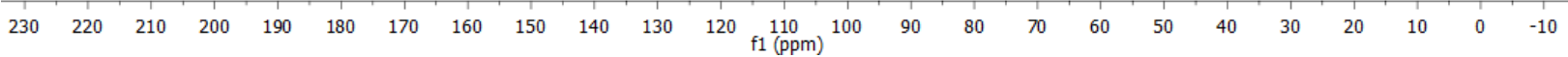


TAMRA-modified tyrocidine A (14): HSQC (DMSO- $d_{6}$ )
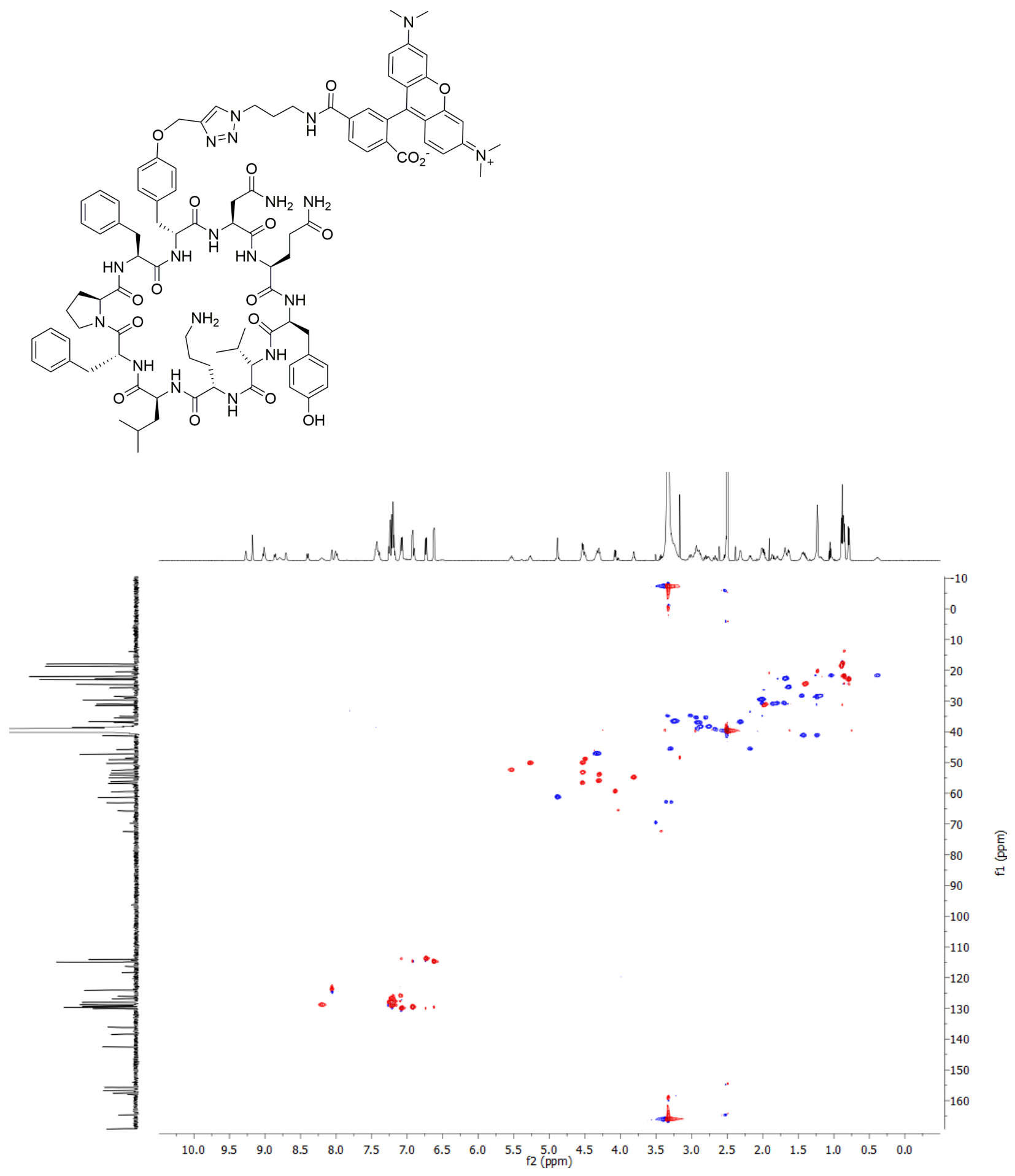
TAMRA-modified tyrocidine A (14): HMBC (DMSO- $d_{6}$ )

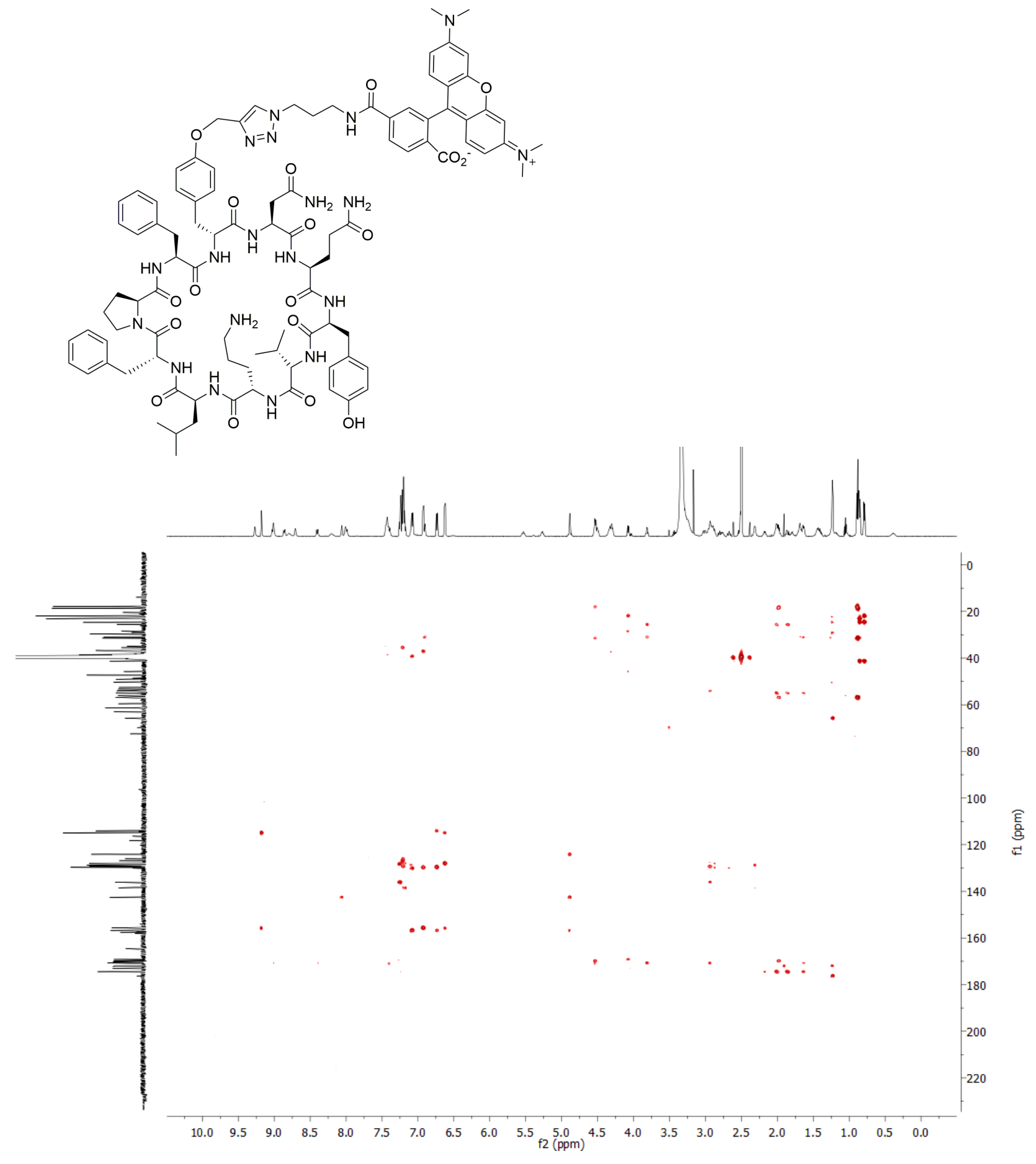


TAMRA-modified tyrocidine A (14): ${ }^{15} \mathrm{~N}-\mathrm{HSQC}\left(\mathrm{DMSO}-d_{6}\right)$
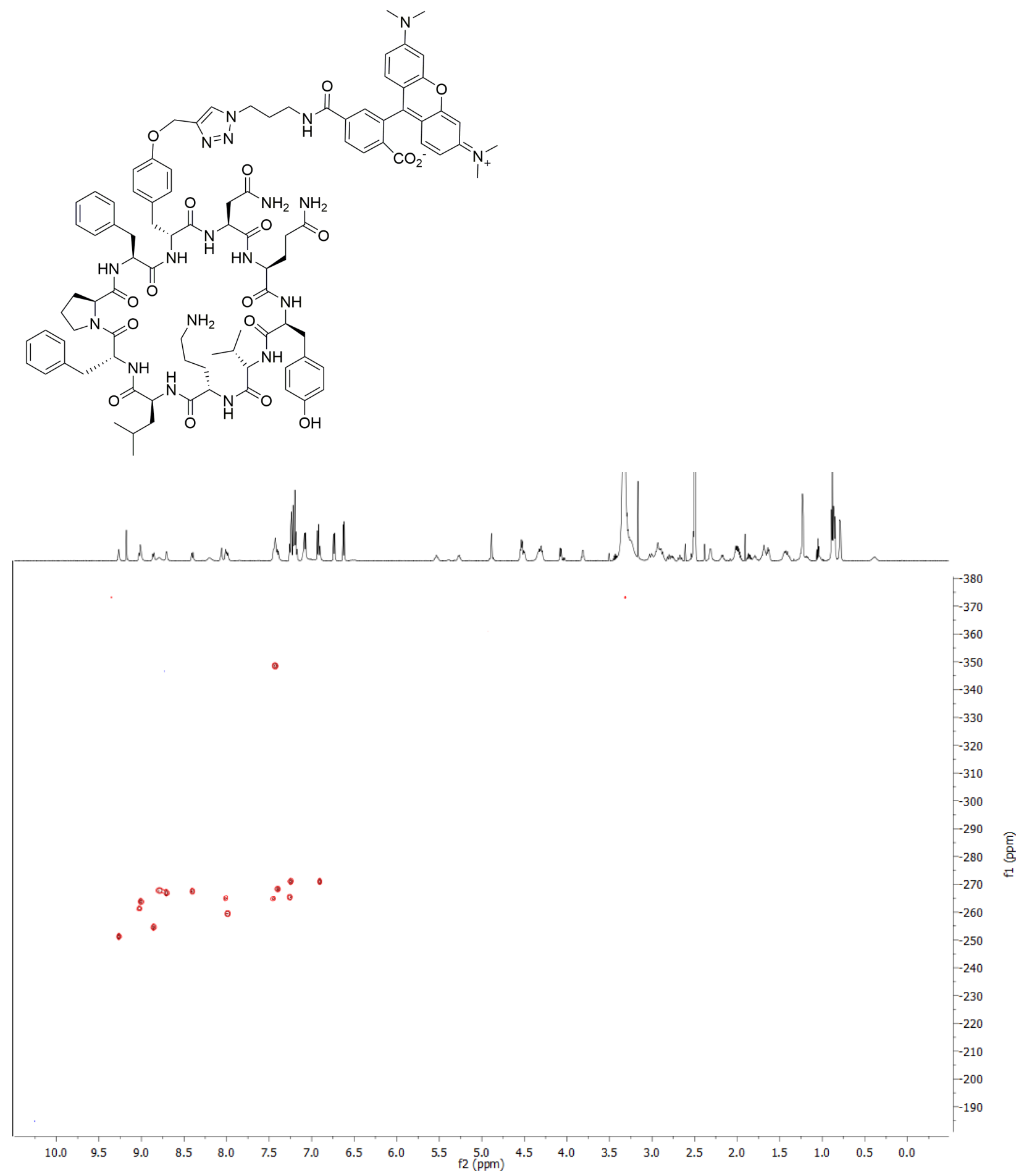


\section{References}

(1) Gruenewald, S.; Mootz, H. D.; Stehmeier, P.; Stachelhaus, T. In Vivo Production of Artificial Nonribosomal Peptide Products in the Heterologous Host Escherichia coli. Appl. Environ. Microbiol. 2004, 70, 3282-3291.

(2) Kries, H.; Wachtel, R.; Pabst, A.; Wanner, B.; Niquille, D.; Hilvert, D. Reprogramming Nonribosomal Peptide Synthetases for "Clickable" Amino Acids. Angew. Chem., Int. Ed. 2014, 53, 10105-10108.

(3) Gibson, D. G.; Young, L.; Chuang, R.-Y.; Venter, J. C.; Hutchison, C. A., III; Smith, H. O. Enzymatic Assembly of DNA Molecules up to Several Hundred Kilobases. Nat. Methods 2009, $6,343-345$.

(4) Studier, F. W. Protein Production by Auto-Induction in High-Density Shaking Cultures. Protein Expr. Purif. 2005, 41, 207-234.

(5) Nakano, M. M.; Marahiel, M. A.; Zuber, P. Identification of a Genetic Locus Required for Biosynthesis of the Lipopeptide Antibiotic Surfactin in Bacillus subtilis. J. Bacteriol. 1988, 170, $5662-5668$.

(6) Stachelhaus, T.; Mootz, H. D.; Marahiel, M. A. The Specificity-Conferring Code of Adenylation Domains in Nonribosomal Peptide Synthetases. Chem. Biol. 1999, 6, 493-505.

(7) Challis, G. L.; Ravel, J.; Townsend, C. A. Predictive, Structure-Based Model of Amino Acid Recognition by Nonribosomal Peptide Synthetase Adenylation Domains. Chem. Biol. 2000, 7, 211-224. 